\title{
Graphene oxide/multi-walled carbon nanotubes as nanofeatured scaffolds for the assisted deposition of nanohydroxyapatite: characterization and biological evaluation
}

\author{
This article was published in the following Dove Press journal: \\ International Journal of Nanomedicine \\ 13 June 2016 \\ Number of times this article has been viewed
}

\author{
Bruno VM Rodrigues ${ }^{1, *}$ \\ Nelly CS Leitel,* \\ Bruno das Neves \\ Cavalcanti ${ }^{2}$ \\ Newton S da Silva ${ }^{3}$ \\ Fernanda R Marciano' \\ Evaldo J Corat ${ }^{4}$ \\ Thomas J Webster ${ }^{5,6}$ \\ Anderson O Lobo' \\ 'Laboratory of Biomedical \\ Nanotechnology, Institute of Research \\ and Development (IP\&D), University \\ of Vale do Paraiba (UNIVAP), Sao Jose \\ dos Campos, Brazil; ${ }^{2}$ Department of \\ Cardiology, Restorative Sciences and \\ Endodontics, School of Dentistry, \\ University of Michigan, Ann Arbor, \\ MI, USA; ${ }^{3}$ Laboratory of Cell Biology \\ and Tissue, Institute of Research \\ and Development (IP\&D), University \\ of Vale Do Paraiba (UNIVAP), \\ ${ }^{4}$ Associated Laboratory of Sensors \\ and Materials, National Institute \\ for Space Research, Sao Jose dos \\ Campos, Brazil; ${ }^{5}$ Department of \\ Chemical Engineering, Northeastern \\ University, Boston, MA, USA; ${ }^{6}$ Center \\ of Excellence for Advanced Materials \\ Research, King Abdulaziz University, \\ Jeddah, Saudi Arabia
}

*These authors contributed equally to this work

Correspondence: Anderson O Lobo Laboratory of Biomedical Nanotechnology, Institute of Research and Development (IP\&D), University of Vale do Paraiba (UNIVAP), I2244-000 Sao Jose dos

Campos, SP, Brazil

Email aolobo@pq.cnpq.br

\begin{abstract}
Nanohydroxyapatite (nHAp) is an emergent bioceramic that shows similar chemical and crystallographic properties as the mineral phase present in bone. However, nHAp presents low fracture toughness and tensile strength, limiting its application in bone tissue engineering. Conversely, multi-walled carbon nanotubes (MWCNTs) have been widely used for composite applications due to their excellent mechanical and physicochemical properties, although their hydrophobicity usually impairs some applications. To improve MWCNT wettability, oxygen plasma etching has been applied to promote MWCNT exfoliation and oxidation and to produce graphene oxide (GO) at the end of the tips. Here, we prepared a series of nHAp/ MWCNT-GO nanocomposites aimed at producing materials that combine similar bone characteristics (nHAp) with high mechanical strength (MWCNT-GO). After MWCNT production and functionalization to produce MWCNT-GO, ultrasonic irradiation was employed to precipitate nHAp onto the MWCNT-GO scaffolds (at 1-3 wt\%). We employed various techniques to characterize the nanocomposites, including transmission electron microscopy (TEM), Raman spectroscopy, thermogravimetry, and gas adsorption (the Brunauer-Emmett-Teller method). We used simulated body fluid to evaluate their bioactivity and human osteoblasts (boneforming cells) to evaluate cytocompatibility. We also investigated their bactericidal effect against Staphylococcus aureus and Escherichia coli. TEM analysis revealed homogeneous distributions of nHAp crystal grains along the MWCNT-GO surfaces. All nanocomposites were proved to be bioactive, since carbonated nHAp was found after 21 days in simulated body fluid. All nanocomposites showed potential for biomedical applications with no cytotoxicity toward osteoblasts and impressively demonstrated a bactericidal effect without the use of antibiotics. All of the aforementioned properties make these materials very attractive for bone tissue engineering applications, either as a matrix or as a reinforcement material for numerous polymeric nanocomposites.
\end{abstract}

Keywords: nanohydroxyapatite, multi-walled carbon nanotubes, graphene oxide, in vitro, bactericidal effect, bioactivity, bone cells, tissue engineering

\section{Introduction}

In regenerative medicine, the reconstruction of fully functional body tissues has become a major challenge over the last several decades. ${ }^{1-3}$ In orthopedic surgery, the pressing need for efficient reconstruction of bone defects arising from tumors, trauma, and bone diseases has led to a crescent search for new and more effective materials. In this context, natural and synthetic polymers, ceramics, and their composites, obtained 
via many processing techniques, have been investigated for improved biomedical applications, more specifically for bone grafting. ${ }^{4-6}$

In tissue engineering, a successful biomaterial must ideally mimic the natural extracellular matrix of the engineered tissue in order to promote cell differentiation and organspecific functions. Thus, for hard tissues, such as skeletal bone and cartilage, there is a crucial need for materials that possess adequate structural stability and an ability to enhance in vivo bone formation.

Among the ceramic materials usually used for biomedical applications, hydroxyapatite $\left(\mathrm{HAp}, \mathrm{Ca}_{10}\left(\mathrm{PO}_{4}\right)_{6}(\mathrm{OH})_{2}\right)$ can be highlighted as an emergent bioceramic due to its chemical and crystallographic similarity to the mineral component of the natural bone. ${ }^{4}$ Due to its microstructure, biocompatibility, and osteoconductivity, nanosized HAp (nanohydroxyapatite, nHAp) has been widely investigated for applications in bone tissue regeneration. ${ }^{4,7-9}$ Nevertheless, the low tensile strength and fracture toughness of nHAp limit its application in large bone defects. In this context, the literature has introduced many different approaches to combine nHAp and different forms of carbon in order to enhance the mechanical properties of nHAp without impairing its bioactivity. ${ }^{9-11}$

Over the last few years, multi-walled carbon nanotubes (MWCNTs) and graphene oxide (GO) have attracted much attention due to their excellent mechanical and physicalchemical properties (low mass, high surface area, and high electrical and thermal conductivity). ${ }^{12-16}$ Combining MWCNTs and GO with HAp in its many forms (such as nano) represents an alternative to improve the chemical, physical, and biological characteristics of polymeric nanocomposites, as well as to generate materials that can mimic bone tissues. ${ }^{11,17-19}$ For example, Lahiri et al ${ }^{20}$ demonstrated that MWCNTs were responsible for increasing the adhesion strength, and spreading and attachment of osteoblasts in HAp/MWCNT nanocomposites. Balani et $\mathrm{al}^{21}$ reported on the improvement of the fracture toughness and crystallinity of the coating of HAp/MWCNT nanocomposites prepared by plasma spraying. Moreover, they showed osteoblast growth and proliferation, an evidence of the nontoxicity of these materials.

Although carbon nanotube (CNT) reinforcement in HAp matrices has been demonstrated, ${ }^{20,22,23}$ as well as low cytotoxicity of these composites, ${ }^{9,20}$ a full report on their physical-chemical properties, biological properties, and their dependence on the MWCNT-GO content is still missing. Recently, our group developed a novel routine to produce large-scale nHAp/MWCNT-GO nanocomposites using a wet-chemical method assisted by ultrasound irradiation. ${ }^{19}$
Therefore, herein, we present for the first time a systematic evaluation of the production and characterization of $\mathrm{nHAp} /$ MWCNT-GO nanocomposites. We evaluated the physical, chemical, and biological properties of nHAp/MWCNT-GO nanocomposites. Besides this, we present dependence between MWCNT-GO content and nHAp precipitation. We performed a wide range of techniques for morphological (field emission gun scanning electron microscopy [FEGSEM] and high-resolution transmission electron microscopy [HRTEM]), surface area (Brunauer-Emmett-Teller [BET] and mercury porosimetry), structural (X-ray diffraction [XRD] and Raman spectroscopy), chemical (Fourier transform infrared spectroscopy), and thermal (thermogravimetry) characterizations. We also studied the biological properties of nHAp/MWCNT-GO nanocomposites, including bioactivity, cytotoxicity, osteoblast adhesion and proliferation, as well as bactericidal activity.

The findings in this paper open up many possible applications of nHAp/MWCNT-GO nanocomposites in bone tissue engineering where improved strength, bone cell responses, and antibacterial properties are also required.

\section{Experimental Materials}

All chemicals used in this work were analytical-grade products and purchased from Sigma-Aldrich Co. (St Louis, MO, USA).

\section{Synthesis of MWCNTs and functionalization (MWCNT-GO)}

The MWCNTs were produced as reported in previous studies. ${ }^{24}$ Briefly, a mixture of camphor $\left(\mathrm{C}_{10} \mathrm{H}_{16} \mathrm{O}, 84 \mathrm{wt} \%\right)$ and ferrocene $\left(\mathrm{Fe}\left(\mathrm{C}_{5} \mathrm{H}_{5}\right)_{2}, 16 \%\right)$ as a catalyst was placed in a thermal chemical vapor deposition furnace and then vaporized at $200^{\circ} \mathrm{C}$ in an antechamber. At atmospheric pressure, the vapor was carried to the chamber of the chemical vapor deposition furnace $\left(850^{\circ} \mathrm{C}\right)$ under nitrogen gas flow (1.5 L min $\mathrm{m}^{-1}$ ), and the MWNCTs were deposited on the wall of the quartz tube. After 5 minutes, the vapor was cut off, and the furnace was cooled to room temperature under $\mathrm{N}_{2}$ flow.

The catalytic particles (Fe) were removed from the MWCNTs by an acid etching treatment. The MWCNTs were subjected to ultrasound irradiation for 5 hours in a $\mathrm{H}_{2} \mathrm{SO}_{4}: \mathrm{HNO}_{3}(3: 1)$ solution and then filtered using a Millipore membrane $(0.45 \mu \mathrm{m})$, washed extensively with water, and finally dried $\left(100^{\circ} \mathrm{C}, 12\right.$ hours $)$. In order to generate superhydrophilic MWCNTs, oxygen-containing groups were incorporated as described in previous work, ${ }^{25}$ in a pulsed direct current plasma reactor with an oxygen flow rate of 
$1 \mathrm{sccm}$, at $-700 \mathrm{~V}$, a pressure of $85 \mathrm{mTorr}$, and a pulse frequency of $20 \mathrm{kHz}$. The superhydrophilic MWCNTs will be further referred to as MWCNT-GO.

\section{Ultrasound-assisted preparation of nHAp/MWCNT-GO nanocomposites}

The nHAp/MWCNT-GO nanocomposites were prepared at different concentrations of MWCNT-GO (1.0, 2.0, and $3.0 \mathrm{wt} \%$ ). For this purpose, calcium nitrate tetrahydrate $\left[\mathrm{Ca}\left(\mathrm{NO}_{3}\right)_{2} \cdot 4 \mathrm{H}_{2} \mathrm{O}\right]$ and diammonium hydrogen phosphate $\left[\left(\mathrm{NH}_{4}\right)_{2} \mathrm{HPO}_{4}\right]$ were dissolved in $50 \mathrm{~mL}$ of deionized water, and MWCNT-GO was added and sonicated (Vibracell Sonics, $500 \mathrm{~W})$ during 30 minutes $(\mathrm{Ca} / \mathrm{P}=1.67) .{ }^{26}$ The $\mathrm{pH}$ was kept at $\sim 10$ by dropwise addition of a $\mathrm{NH}_{4} \mathrm{OH}$ solution $(25 \%)$. The remaining solid was allowed to settle for 120 hours until maturation and then was filtered, waterwashed, and dried at $60^{\circ} \mathrm{C}$ (48 hours). For further analysis, nHAp/MWCNT-GO nanocomposites were milled in an analytical mill (IKA, model A11), as well as pristine nHAp and MWCNT-GO as control samples.

\section{Nanocomposite characterization}

Scanning electron microscopy (SEM) and FEG-SEM were performed using two different microscopes, a Zeiss/EVO MA10 operated at $20 \mathrm{kV}$ to reach a magnification of $\times 15,000$ and a Philips XL30 field emission gun operated at $10 \mathrm{kV}$ to reach a magnification up to $\times 30,000$. All samples were previously coated with a thin layer of gold $(\sim 10 \mathrm{~nm})$ using a sputter coater.

HRTEM was performed using a FEI Tecnai G ${ }^{2}$ F20 microscope. The MWCNT-GO and nHAp/MWCNT-GO powder samples were dispersed in $50 \mathrm{~mL}$ of water under ultrasound and then deposited on copper TEM grids (300 mesh).

The crystallinity and phase of the nanopowders (nHAp, MWCNT-GO, and nHAp/MWCNT-GO nanocomposites) were characterized by XRD (PANalytical X'Pert Pro diffractometer) using a monochromatic $\mathrm{CuK} \alpha \mathrm{X}$-ray radiation. The data were collected over a range of $20^{\circ}-60^{\circ}$ with a scanning step of $0.08^{\circ} \mathrm{min}^{-1}$. Highscore 3.0a software (PaNalytical, Almelo, the Netherlands) was used to identify the phase.

The thermal behavior of nHAp, MWCNT-GO, and nHAp/MWCNT-GO nanocomposites was evaluated using a Netzsch STA 449-Jupiter. The samples (6-8 mg) were placed on a platinum pan and heated from $25^{\circ} \mathrm{C}$ to $1,000^{\circ} \mathrm{C}$ at $10^{\circ} \mathrm{C} \mathrm{min}^{-1}$ under a nitrogen-purged atmosphere $\left(50 \mathrm{~mL} \mathrm{~min}^{-1}\right)$.

A mercury porosimeter (Pore Master 60-GT; Quantachrome Instruments, Boynton Beach, FL, USA) was employed to characterize the total area of the nanocomposites through their macropores' size distribution, while BET was used to evaluate the micro- and mesopores based on the classical helium-void volume method. Quantachrome Pore Master (version 7.01), Quantachrome NovaWin 2, and Quantachrome Instruments (version 2.2) software were used for data analysis.

Attenuated transmission reflectance Fourier transform infrared (ATR-FTIR; Perkin-Elmer Spotlight 400 FTIR Imaging System) was performed, and data were collected at room temperature in the 4,000-700 $\mathrm{cm}^{-1}$ region.

Raman spectra were recorded at ambient temperature using a Horiba microprobe system, employing an argon laser for excitation $(\lambda=514.5 \mathrm{~nm}$ ) with a laser power of $\sim 6 \mathrm{~mW}$.

\section{Bioactivity assay}

For the bioactivity assay, a simulated body fluid (SBF) $(1.5 x)^{27}$ solution was prepared via dissolution of different salts in a Tris $4.037 \mathrm{~g} \mathrm{~L}^{-1}$ buffer solution ( $\mathrm{pH} 7.4$, simulating blood plasma), as described elsewhere. ${ }^{11}$

The nanocomposites were immersed in polyethylene containers with an SBF solution (1.5x) $\left(1 \mathrm{mg} \mathrm{mL}^{-1}\right)$ and placed in a refrigerated benchtop incubator (Cientec CT-713). The samples were centrifuged $\left(75 \mathrm{rpm}, 36.5^{\circ} \mathrm{C}\right)$ at different times (7 and 21 days). After incubation, the nanocomposites were washed with deionized water $\left(80^{\circ} \mathrm{C}\right)$ for removal of the salts and then filtered and dried at room temperature for 24 hours.

After biomineralization, the nanocomposites were characterized via the same techniques previously described (ie, SEM, ATR-FTIR, and XRD).

\section{Assays for cell viability and proliferation}

Analysis of cell viability and proliferation was performed using a human osteoblast cell line (MG-63, CC-2538; Lonza, Walkersville, MD, USA). The Ethics Committee/Institutional Review Board from the University of Vale do Paraiba/IP\&D (Comitê de Ética em Pesquisa da Universidade do Vale do Paraíba) did not require that ethical approval be sought or obtained for the use of cell lines. The cells were cultured in a specific growth medium (OGM, CC-3207; Lonza) and incubated in a $5 \% \mathrm{CO}_{2}$ atmosphere at $37^{\circ} \mathrm{C}$ in plastic cell culture flasks $\left(75 \mathrm{~cm}^{2}\right)$. Scaffolds were prepared by simply mixing the nHAp/MWCNT-GO nanocomposites with hyaluronic acid $(50 / 50, w / w, \%)$. A thin layer of this mixture was placed in the upper chambers of the transwell plates (Ref\#3412 Costar ${ }^{\circledR}$; Corning, Corning, NY, USA) with a membrane pore size of $5 \mu \mathrm{m}$ allowing its contact with osteoblasts (Figure 1).

The control groups were established as follows: a negative control (only the culture medium and no cells), a positive control (grown cells in culture medium), and nHAp, 


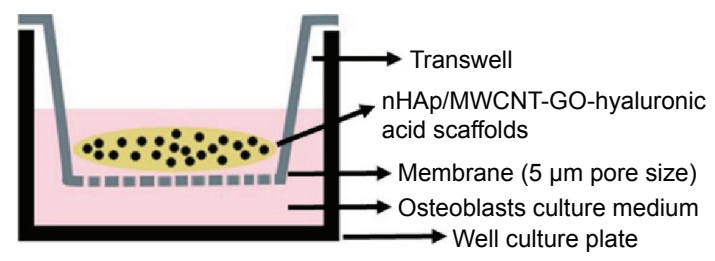

Figure I Figure representing the transwell plates with the nanocomposite scaffolds.

Abbreviations: $\mathrm{nHAp}$, nanohydroxyapatite; MWCNT, multi-walled carbon nanotube; GO, graphene oxide.

MWCNT-GO, as well asnHAp/MWCNT-GOnanocomposites in hyaluronic acid generating the scaffolds, as previously discussed.

\section{Cytotoxicity assays}

For the cytotoxicity assays, MG-63 cells were seeded in six-well plates $\left(1 \times 10^{4}\right.$ cells/well). The cytotoxicity levels were evaluated through the contact between the cells and the scaffolds inserted in the upper chambers of the transwell plates. After 7 days, the chambers were removed, and the cells were washed with phosphate-buffered saline (PBS; Thermo Fisher Scientific, Waltham, MA, USA) and fixed with $10 \%$ trifluoroacetic acid ( 1 hour at $4^{\circ} \mathrm{C}$ ). After washing and drying, the cells were stained with $0.4 \%$ sulforhodamine B solution in 1\% acetic acid (Sigma-Aldrich) for 30 minutes at room temperature. The cells were rewashed with $1 \%$ acetic acid to remove the non-bonded dye and left to dry. The bonded dye was solubilized in $1 \mathrm{mM}$ Tris (Sigma-Aldrich), and the solution was stirred and transferred to a 96-well plate for absorbance evaluation in a microplate spectrophotometer (Synergy HT Multi-Detection; BioTek, Winooski, VT, USA) at $570 \mathrm{~nm}$. The experiments were performed in triplicate. The data were expressed as the average with standard deviation. Statistical comparisons were carried out via one-way analysis of variance (ANOVA) and multiple comparisons Tukey's test to determine any significant differences between groups $(P<0.05)$.

\section{Study of the bactericidal effect of the nHAp/MWCNT-GO nanocomposites}

To evaluate the bacterial effect of samples, Escherichia coli (ATCC 25922) and Staphylococcus aureus (ATCC 25923) strains were used as Gram-negative and Gram-positive bacteria models, respectively. The bacteria were seeded in Luria-Bertani (LB) medium (10 $\mathrm{g} \mathrm{L}^{-1}$ of tryptone, $5 \mathrm{~g}$ of yeast extract, and $10 \mathrm{~g} \mathrm{~L}^{-1}$ of $\mathrm{NaCl}$ ) at $37^{\circ} \mathrm{C}$ and diluted in PBS to $1 \mathrm{mg} \mathrm{mL}^{-1}$ and sterilized at $120^{\circ} \mathrm{C}$ in an autoclave for 15 minutes.
Twenty-four-well plates containing $1,000 \mu \mathrm{L}$ of LB medium with $5 \mu \mathrm{L}\left(\sim 10^{5} \mathrm{CFU} \mathrm{mL}^{-1}\right)$ of each bacterium were used. The bacteria were exposed to two concentrations of the diluted samples in PBS $\left(0.01\right.$ and $\left.0.1 \mathrm{mg} \mathrm{mL}^{-1}\right)$. The tests were performed in triplicate. A broad-spectrum gentamicin antibiotic was used as a positive control, whereas wells containing only bacteria in LB medium were used for negative controls. The plates were incubated at $37^{\circ} \mathrm{C}$ during 3 hours for $E$. coli and 12 hours for $S$. aureus according to strain growth curves previously investigated. ${ }^{28,29}$

Optical density (OD) analysis was performed after the incubation period. In a typical experiment, $10 \mu \mathrm{L}$ was withdrawn and read on a microplate spectrophotometer (Synergy HT Multi-Detection; BioTek) at $520 \mathrm{~nm}$. Equation 1 was used to calculate the bacterial activity. ${ }^{30}$

$$
R(\%)=\frac{(B-C)}{B} \times 100,
$$

where $R$ is the bactericidal action expressed in percentage, $B$ is the average value of OD in the negative control, and $C$ is the average value of OD in the test groups. Statistical comparisons were carried out via one-way ANOVA and multiple comparisons Tukey's test to determine any significant differences between groups $(P<0.05)$.

\section{Results and discussion Nanocomposites characterization MWCNT-GO structural characterization}

Figure 2 shows the HRTEM micrographs of the pristine MWCNTs (Figure 2A) and MWCNT-GO (Figure 2B and C). The MWCNTs presented bamboo-like structures with average diameters of $25 \mathrm{~nm}$ and $\sim 30$ walls. It is clear that the CNT walls were affected by the chloridic acid treatment, which led to defects and entangled structures. Figure 2B shows a region where MWCNT-GO did not present structural defects in their extension, since we observed that the ends of the tubes were closed. On the other hand, Figure $2 \mathrm{C}$ shows the exfoliated MWCNT tips exposing their graphene-like structure ( $\sim 50 \mathrm{~nm}$ sheets).

Figure 2D shows the first- and second-order Raman scattering spectra of MWCNTs and MWCNT-GO. The D band is usually attributed to the disorder and imperfection of the carbon crystallites. The $\mathrm{G}$ band is assigned to one of the two $\mathrm{E}_{2} \mathrm{~g}$ modes corresponding to stretching vibrations in the basal plane ( $\mathrm{sp}^{2}$ domains) of single-crystal graphene. ${ }^{31}$ The high-intensity $\mathrm{G}^{\prime}$ band reveals that these materials present high structural quality. ${ }^{32}$ In the MWCNT-GO first-order Raman 

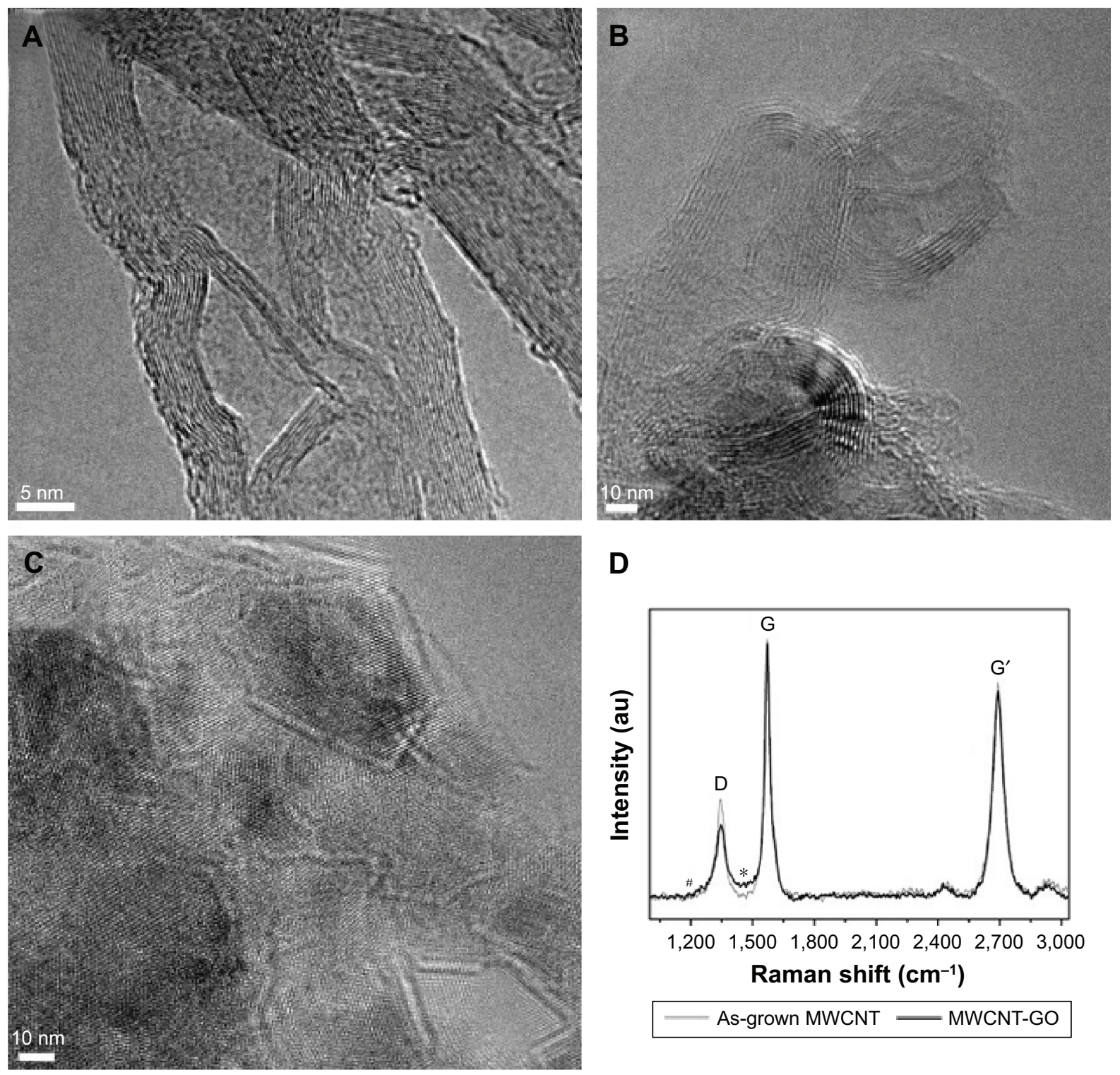

D

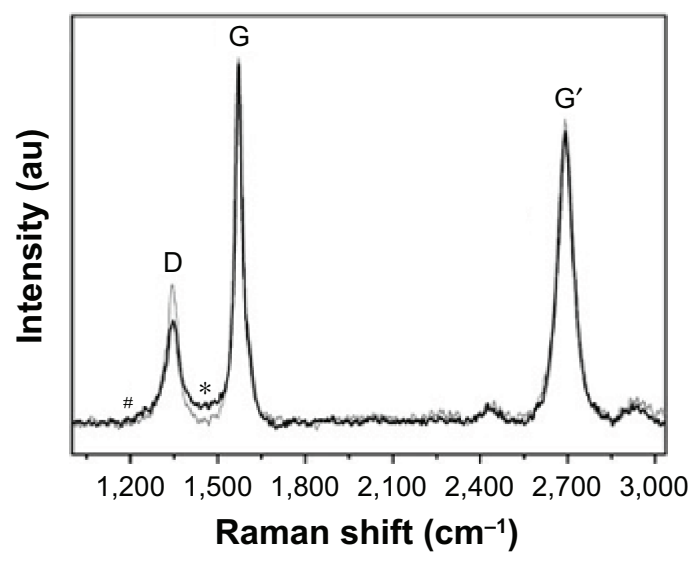

As-grown MWCNT MWCNT-GO

Figure 2 Structural analyses of MWCNT and MWCNT-GO.

Notes: HRTEM shows (A) the typical bamboo-like structure and defects of MWCNT, (B) the details of the end of the MWCNT tips, and (C) the graphene sheets exposed by MWCNT after oxygen plasma treatment. (D) The first- and second-order Raman spectra of MWCNT and MWCNT-GO. * and \# correspond, respectively, to peaks at 1,480 and $\sim 1,200 \mathrm{~cm}^{-1}$.

Abbreviations: MWCNT, multi-walled carbon nanotube; GO, graphene oxide; HRTEM, high-resolution transmission electron microscopy; au, arbitrary units.

spectra, for appropriate deconvolution fitting, two Gaussian peaks centered at $\sim 1,250(\#)$ and $1,480 \mathrm{~cm}^{-1}(*)$ were added necessarily. Probably, the shoulder has its origin in the double resonance process because its Raman shift $\left(\sim 1,200 \mathrm{~cm}^{-1}\right)$ is a point on the graphene phonon dispersion curves..$^{31}$ The origin of the $1,480 \mathrm{~cm}^{-1}\left(^{*}\right)$ band is probably correlated with the polar group grafting onto the MWCNT-GO surfaces. ${ }^{33}$

It is well known that MWCNTs are graphene sheets rolled into cylinders. Moreover, graphene sheet rolling up into a tube is a standard way to illustrate CNT formation. Nanotube tips are defective and interact directly with plasma, causing tip exfoliation (as shown in Figure 2C). Further, in our nanotubes, only a few sidewalls were discreetly affected by hydrochloric acid treatment (as shown in Figure 2A). However, depending on plasma conditions and time, we could partially etch the CNT tips or simply attach oxygen groups to them without exfoliation. Nevertheless, we showed that when the oxygen plasma etching is carried out at higher plasma pressures ( $>180 \mathrm{mTorr}$ ) or for longer process times, we could obtain graphene sheets (as shown in Figure 2C). Meanwhile, we showed in a previous study that oxygen plasma treatment not only exposed the graphene sheets but also incorporated $\sim 22 \%$ of oxygen content and consequently attached carboxylic and carboxylate groups. ${ }^{34}$ 


\section{nHAp/MWCNT-GO morphological characterization via FEG-SEM and HRTEM}

The FEG-SEM micrographs of the nHAp/MWCNT-GO nanocomposites and pristine nHAp and MWCNT-GO are presented in Figure 3A-E. Figure 3A shows MWCNT-GO of varied lengths and with irregular surfaces with some whitish regions pointing out the exfoliation due to the functionalization process. Figure $3 \mathrm{~B}$ reveals the agglomeration of the nHAp crystals, and some plaques (flattened regions) were observed all along the surface, in a way similar to nHAp/MWCNT-GO1\% (Figure 3C). However, at higher concentrations of MWCNT-GO ( 2 and $3 \mathrm{wt} \%$; Figure $3 \mathrm{D}$ and $\mathrm{E}$ ), it was possible to observe nHAp covering the MWCNT-GO (indicated by arrows).

Zhao et $\mathrm{al}^{35}$ reported the production of CNTs/HAp nanocomposites with different CNT contents by an in situ method followed by purification with nitric acid. They showed the adhesion of the HAp crystals along the CNT surface via TEM. In the same direction, Núñez et $\mathrm{al}^{36}$ reported the growth of nHAp on CNTs via a wet-chemical in situ precipitation route, showing the presence of nHAp on the surface of the MWCNT-GO confirmed by the change of the crystallographic plane.

The nucleation of nHAp along the MWCNT-GO is highly favored due to the presence of functional groups on the MWCNT-GO surface. The interaction models between nHAp and CNTs are usually based on the arrangement of the $\mathrm{Ca}$ atoms from HAp in the plane (3 00 ) with $\mathrm{C}$ atoms from the CNTs, in a hexagonal lattice, with no chemical interaction except van der Waals forces. However, nHAp growth on oxygen-containing surfaces, via a wet-chemical method, is described as a chemical interaction between $\mathrm{Ca}^{2+}$ ions and the functional groups where the oxygen atom is present. ${ }^{37-39}$

Figure 4 presents the HRTEM micrographs of the nanocomposites at the lowest and highest concentrations of MWCNT-GO (ie, 1 and $3 \mathrm{wt} \%$ ). It can be observed that the synthesized nHAp itself corresponded to dense agglomerates of small nanorod particles. As shown in Figure 4, the synthesized nHAp exhibited a uniform size, $\sim 15 \mathrm{~nm}$ in diameter and 45-70 nm in length. At the lowest MWCNT-GO concentration ( $1 \mathrm{wt} \%$; Figure $4 \mathrm{~A}$ ), we observed many free nHAp crystal grains, although a uniform coverage by nHAp crystals could be observed along the carbon scaffold. Conversely, at the highest MWCNT-GO concentration ( $3 \mathrm{wt} \%$; Figure 4B-D), we observed a decrease in the number of free nHAp crystals, whereas the number of nHAp crystal grains covering the MWCNT-GO surface increased.

\section{Raman spectroscopy}

Figure 5A shows the Raman spectra of nHAp and nHAp/ MWCNT-GO composites. All spectra were normalized by the intense nHAp line at $962 \mathrm{~cm}^{-1}$, which is characteristic of crystallized HAp. Bands of lower intensities were observed at $\sim 420,580$, and $1,050 \mathrm{~cm}^{-1}$. The last one is assigned to apatite phosphate groups and is observed only in well-crystallized nHAp..$^{40}$ The other bands are attributed to other forms of apatites such as octacalcium phosphate and dicalcium phosphate dehydrates. ${ }^{40}$ The $\mathrm{P}-\mathrm{O}$ stretching
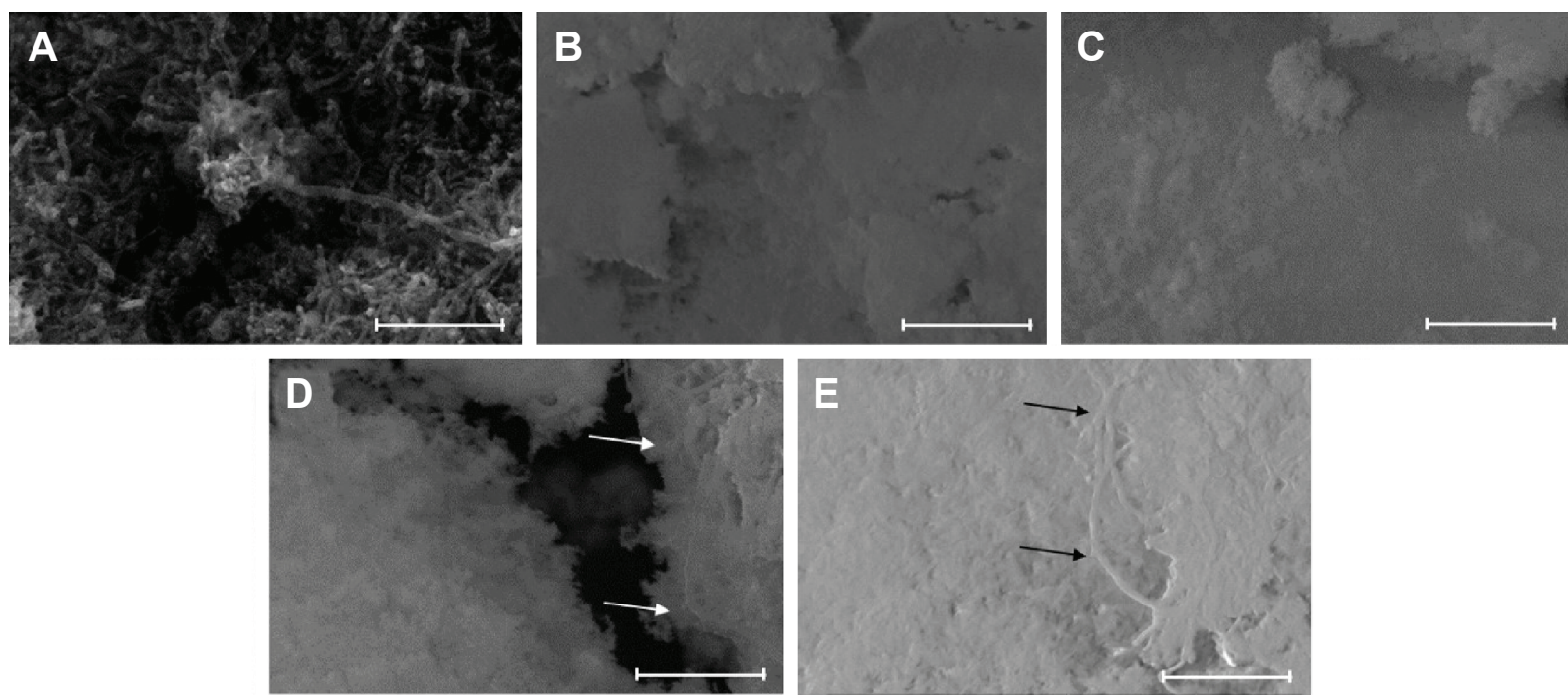

Figure 3 Morphological analysis of MWCNT-GO, nHAp, and nHAp/MWCNT-GO nanocomposites.

Notes: FEG-SEM micrographs with a magnification of $\times 30,000$ of (A) MWCNT-GO, (B) nHAp, (C) nHAp/MWCNT-GOI\%, (D) nHAp/MWCNT-GO2\%, and (E) nHAp/ MWCNT-GO3\%. Scale bar: I $\mu \mathrm{m}$. Both black and white arrows show nHAp covering MWCNT-GO.

Abbreviations: FEG-SEM, field emission gun scanning electron microscopy; MWCNT, multi-walled carbon nanotube; GO, graphene oxide; nHAp, nanohydroxyapatite. 

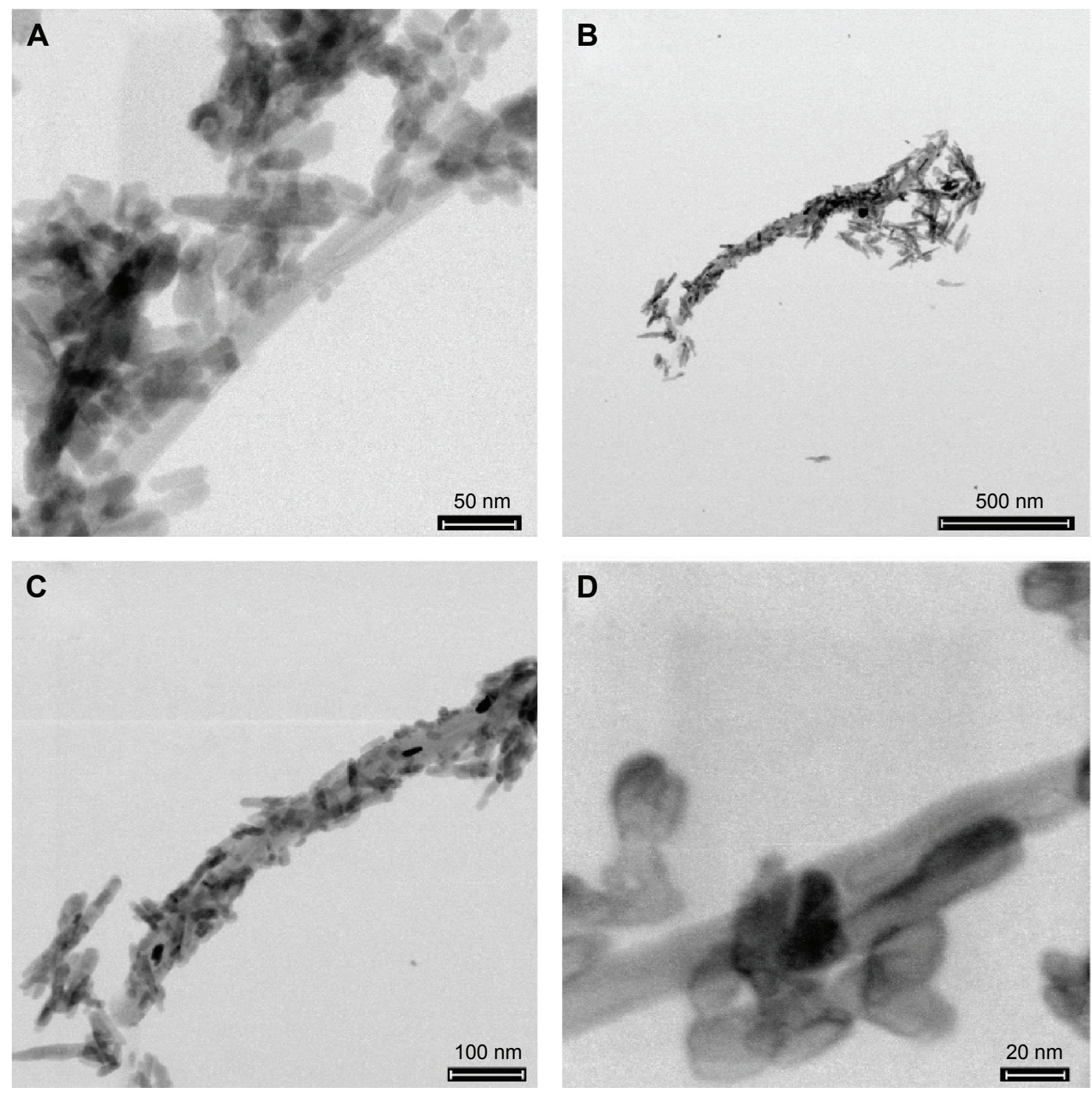

Figure 4 Structural details of nHAp/MWCNT-GO nanocomposites.

Notes: HRTEM micrographs of (A) nHAp/MWCNT-GOI\% and (B-D) nHAp/MWCNT-GO3\%.

Abbreviations: HRTEM, high-resolution transmission electron microscopy; nHAp, nanohydroxyapatite; MWCNT, multi-walled carbon nanotube; GO, graphene oxide.

infrared mode, which appears at $\sim 962 \mathrm{~cm}^{-1}$ in the spectra of all the samples, is attributed to phosphates. The $\mathrm{D}$ and $\mathrm{G}$ bands due to CNT inclusion appear at 1,350 and $1,580 \mathrm{~cm}^{-1}$, respectively.

Figure 5B shows the evolution of the ratio between integrated intensities of $\mathrm{G}$ band and the $962 \mathrm{~cm}^{-1} \mathrm{nHAp}$ line $\left(I_{\mathrm{G}} I_{\mathrm{HA}}\right)$ as a function of CNT concentration in the composite. It clearly shows a linear dependence, as expected.

\section{Thermogravimetric analysis}

Figure 6 presents the thermogravimetric and derivative thermogravimetric curves of pristine MWCNT-GO, pristine nHAP, and nanocomposites based on nHAp/MWCNT-GO. As shown in Figure 6A, no mass loss was observed in
MWCNT-GO up to $500^{\circ} \mathrm{C}$. On the other hand, a massive loss of mass was observed in the range of $500^{\circ} \mathrm{C}-1,000^{\circ} \mathrm{C}$ (56.5\%), which was probably due to the thermal decomposition of $\mathrm{COOH}$ and carboxylate groups with consequent release of $\mathrm{CO}_{2(\mathrm{~g})}$. In a previous study, Hwang et $\mathrm{l}^{41}$ reported the thermal stability of pristine MWCNTs, also under $\mathrm{N}_{2}$, and verified only a few percent loss of mass up to $800^{\circ} \mathrm{C}$, which was probably due to the absorbed humidity.

As shown in Figure 6A and B, pristine nHAp presented three stages of mass loss, in the range of $25^{\circ} \mathrm{C}-120^{\circ} \mathrm{C}$ (loss of $4.58 \%$ ), $120^{\circ} \mathrm{C}-390^{\circ} \mathrm{C}$ (loss of $5.78 \%$ ), and $390^{\circ} \mathrm{C}-500^{\circ} \mathrm{C}$ (loss of $1.1 \%$ ), which can be mainly related to partial removal of the chemically and physically adsorbed water, as well as lattice water. From $500^{\circ} \mathrm{C}$ to $1,000^{\circ} \mathrm{C}$, the mass of nHAp slightly 

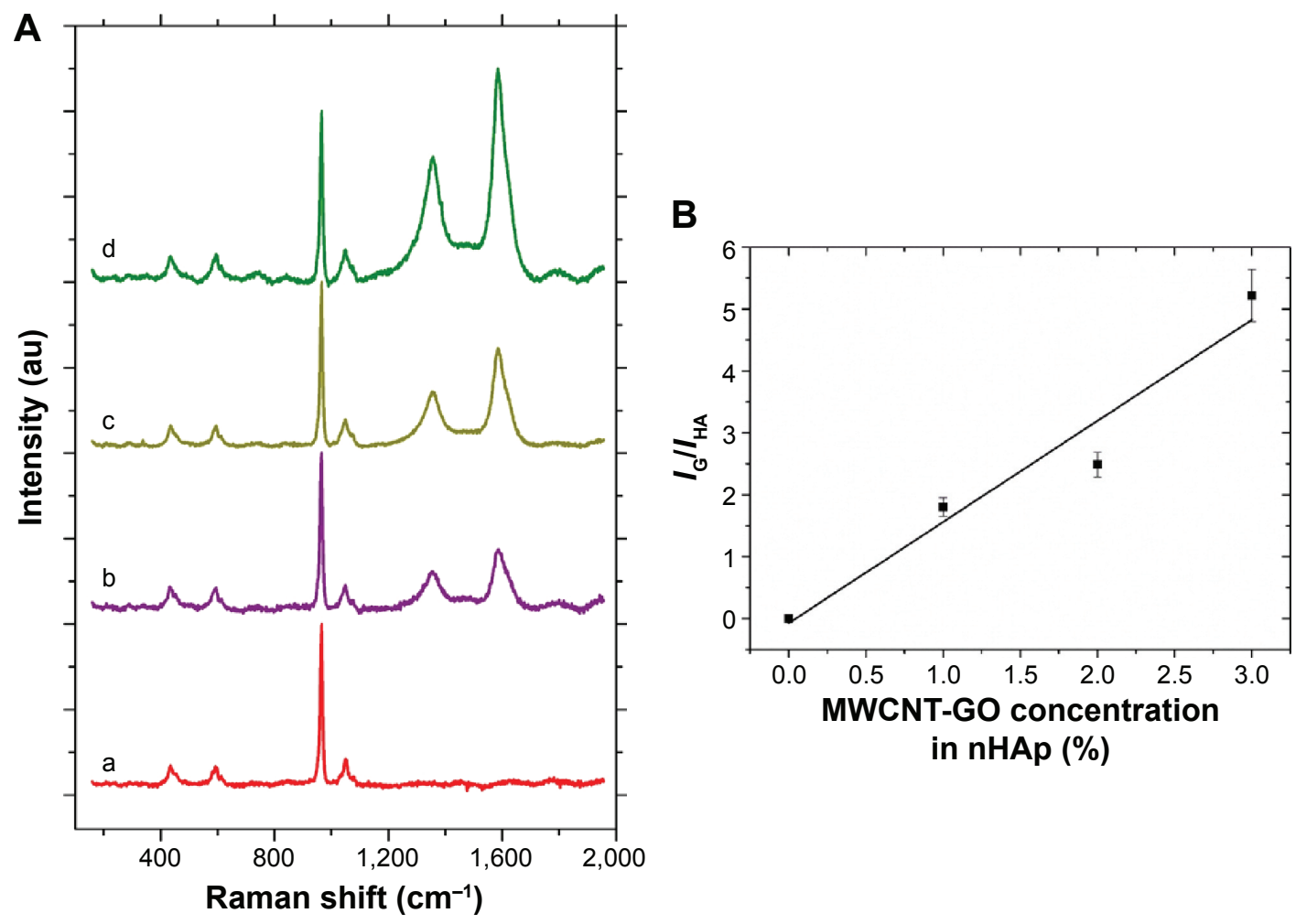

Figure 5 Raman analysis of nHAp, MWCNT-GO, and nHAp/MWCNT-GO nanocomposites.

Notes: (A) Raman spectra of (a) nHAp, (b) nHAp/MWCNT-GOI\%, (c) nHAp/MWCNT-GO2\%, and (d) nHAp/MWCNT-GO3\%. (B) Ratio between integrated intensities of $G$ band and the $962 \mathrm{~cm}^{-1}$ nHAp line $\left(I_{G} I_{\mathrm{HA}}\right)$ as a function of MWCNT-GO concentration in the composite.

Abbreviations: nHAp, nanohydroxyapatite; MWCNT, multi-walled carbon nanotube; GO, graphene oxide; au, arbitrary units.

changed $(0.11 \%)$. Meejoo et al ${ }^{42}$ reported on the narrowing of the $\mathrm{OH}^{-}$band $\left(3,500 \mathrm{~cm}^{-1}\right.$, FTIR results) when nHAp was subjected to elevated temperatures $\left(>800^{\circ} \mathrm{C}\right)$. Furthermore, at high temperatures $\left(>600^{\circ} \mathrm{C}\right)$, the slight mass loss can also be attributed to the decarboxylation of the nHAp, which releases $\mathrm{CO}_{2(\mathrm{~g})}$, and condensation of $\mathrm{HPO}_{4}^{2-}$ releasing water.

Regarding the nanocomposites (Figure 6A and B), different stages of mass loss were observed, which were attributed to the presence of both nHAp and MWCNT-GO in their composition. The increase in MWCNT-GO concentration $(1 \%-3 \%)$ increased the hydrophilic character of the nanocomposites, confirmed by the raise of mass loss up to $500^{\circ} \mathrm{C}$. Since MWCNT-GO itself presented a typical hydrophobic character (no mass loss up to $500^{\circ} \mathrm{C}$ ), as it was not previously submitted to a process of wetting, it is assumed that all mass loss in the nanocomposites in this interval was due to (i) the presence of nHAp and/or (ii) the presence of "wet MWCNT-GO", due to water soaking during the nanocomposite preparation.

At lower concentrations of MWCNT-GO (1\% and 2\%), the mass loss from $25^{\circ} \mathrm{C}$ to $500^{\circ} \mathrm{C}$ (essentially water) was significantly lower than the one observed in pristine nHAp $(11.5 \%)$. However, the increase in MWCNT-GO concentration led to higher mass loss in this temperature interval, from
$3.80 \%$ (MWCNT-GO1\%) to $16.84 \%$ (MWCNT-GO3\%), pointing out the increase in the hydrophilic character of the nanocomposites.

A plausible explanation to this effect relies on the increase of nHAp covering the MWCNT-GO surface as its concentration increases. At the lowest concentration of MWCNT-GO1\%, however, the adsorption of nHAp and consequent establishment of electrostatic interactions and hydrogen bonds with the carboxyl and carboxylate groups from MWCNT-GO would have decreased the nHAp hydrophilic character compared to the pristine nHAp crystals themselves. Nevertheless, the increase in MWCNT-GO concentration ( $2 \%$ and $3 \%$ ) would have favored the nHAp adsorption all along the surface (confirmed by TEM analysis; Figure 4), increasing the local and global interactions with water molecules and leading to nanocomposites with a higher hydrophilic character (Figure 7). To corroborate these results, we performed BET surface area and mercury porosimetry analyses.

\section{BET surface area analysis and mercury porosimetry}

Table 1 shows the textural properties of all nanocomposites investigated from their $\mathrm{N}_{2}$ adsorption/desorption isotherms. When compared to MWCNT-GO $\left(39 \mathrm{~m}^{2} \mathrm{~g}^{-1}\right)$, the BET 

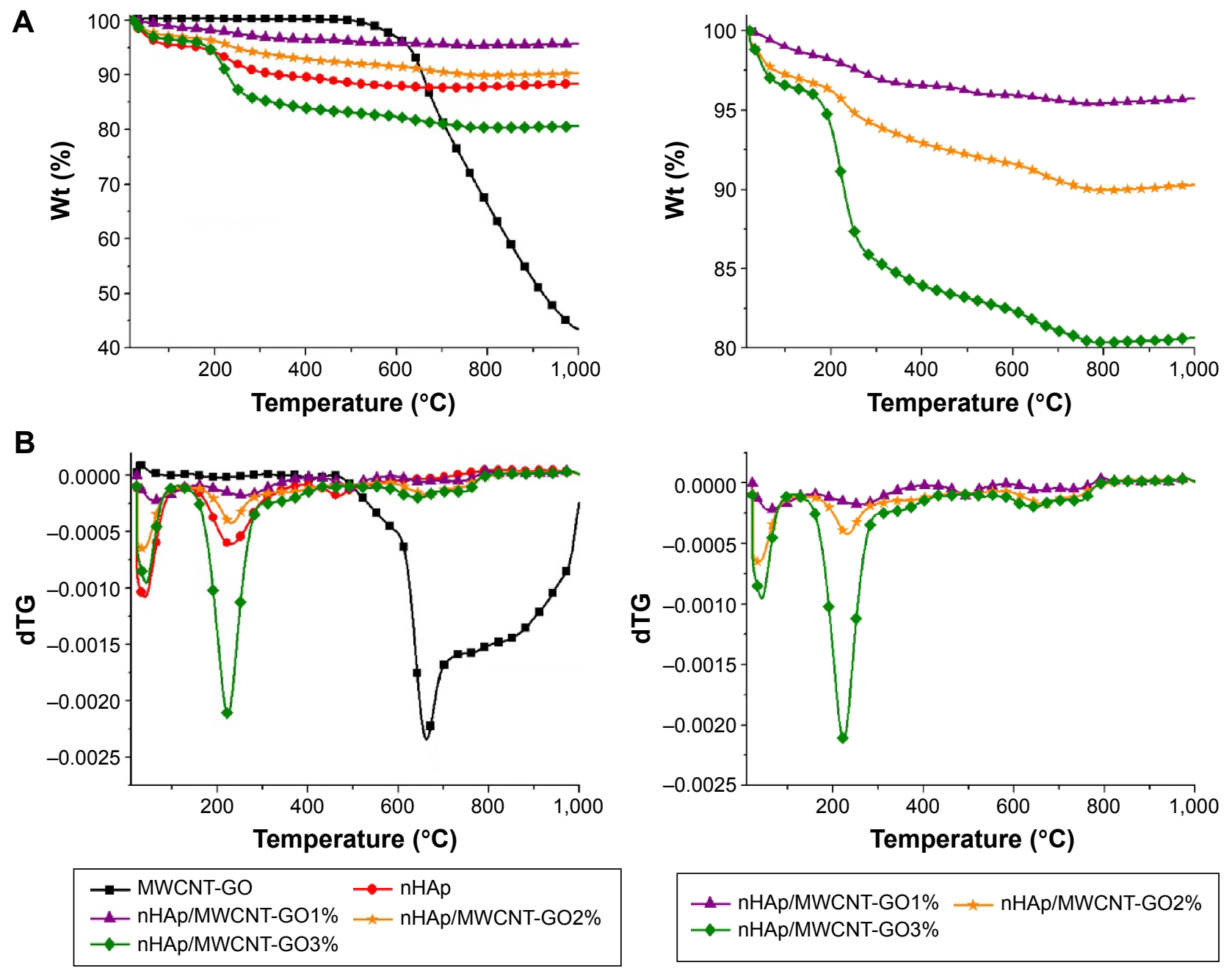

Figure 6 Thermal analysis of nHAp, MWCNT-GO, and nHAp/MWCNT-GO nanocomposites.

Notes: (A) TG and (B) dTG curves of pristine MWCNT-GO, pristine nHAP, and nanocomposites based on nHAp/MWCNT-GO ( $\mathrm{N}_{2}$ atmosphere at $50 \mathrm{~mL} \mathrm{~min}^{-1}$ and heating rate of $\left.10^{\circ} \mathrm{C} \mathrm{min}^{-1}\right)$.

Abbreviations: TG, thermogravimetric; dTG, derivative thermogravimetric; MWCNT, multi-walled carbon nanotube; GO, graphene oxide; nHAp, nanohydroxyapatite; Wt, weight.

surface area of nHAp $\left(54.2 \mathrm{~m}^{2} \mathrm{~g}^{-1}\right)$ increased. Meanwhile, for the nHAp/MWCNT-GO nanocomposites, these values continued to increase. That is an interesting result, and it could be directly related to the higher mean pore diameter of nHAp $(6.89 \mathrm{~nm})$ compared to MWCNT-GO (3.12 nm). On the other hand, the nanocomposites presented similar mean pore diameters. More interesting than pore diameter and surface area is their relationship with thermal analysis and water loss. As expected, the nanocomposite with the highest surface area and mean pore diameter (nHAp/ MWCNT-GO3\%, $73.5 \mathrm{~m}^{2} \mathrm{~g}^{-1}$ and $3.45 \mathrm{~nm}$, respectively) also presented the highest water loss up to $500^{\circ} \mathrm{C}$ (thermogravimetric analysis [TGA]; Figure 6).

Table 1 shows the mercury porosimetry analysis of all the nanocomposites. These data are interesting and complementary to BET analysis. We noticed that the porosity presented by MWCNT-GO (75.7\%) was indeed higher than
nHAp (48.7\%), which was comprehensible due to the high aspect ratio of the first. On the other hand, we noticed that the porosity presented by all nHAp/MWCNT-GO nanocomposites decreased compared to MWCNT-GO, ranging from $64.2 \%$ to $69.4 \%$. Nevertheless, all the nHAp/MWCNT-GO scaffolds showed high porosity $(\sim 60 \%-70 \%)$. This highly porous structure probably may favor cell proliferation and infiltration leading to a better bone tissue engineering material. However, regarding material morphology, porous bioceramic configurations required for cell ingrowth offer highly irregular surfaces that may also promote bacterial colonization. ${ }^{43}$

\section{Biomineralization}

Generally, the in vitro calcification ability of biomaterials has a direct correlation with the bone-bonding ability in vivo. ${ }^{44}$ Bioactivity is a result of the chemical reactions occurring 

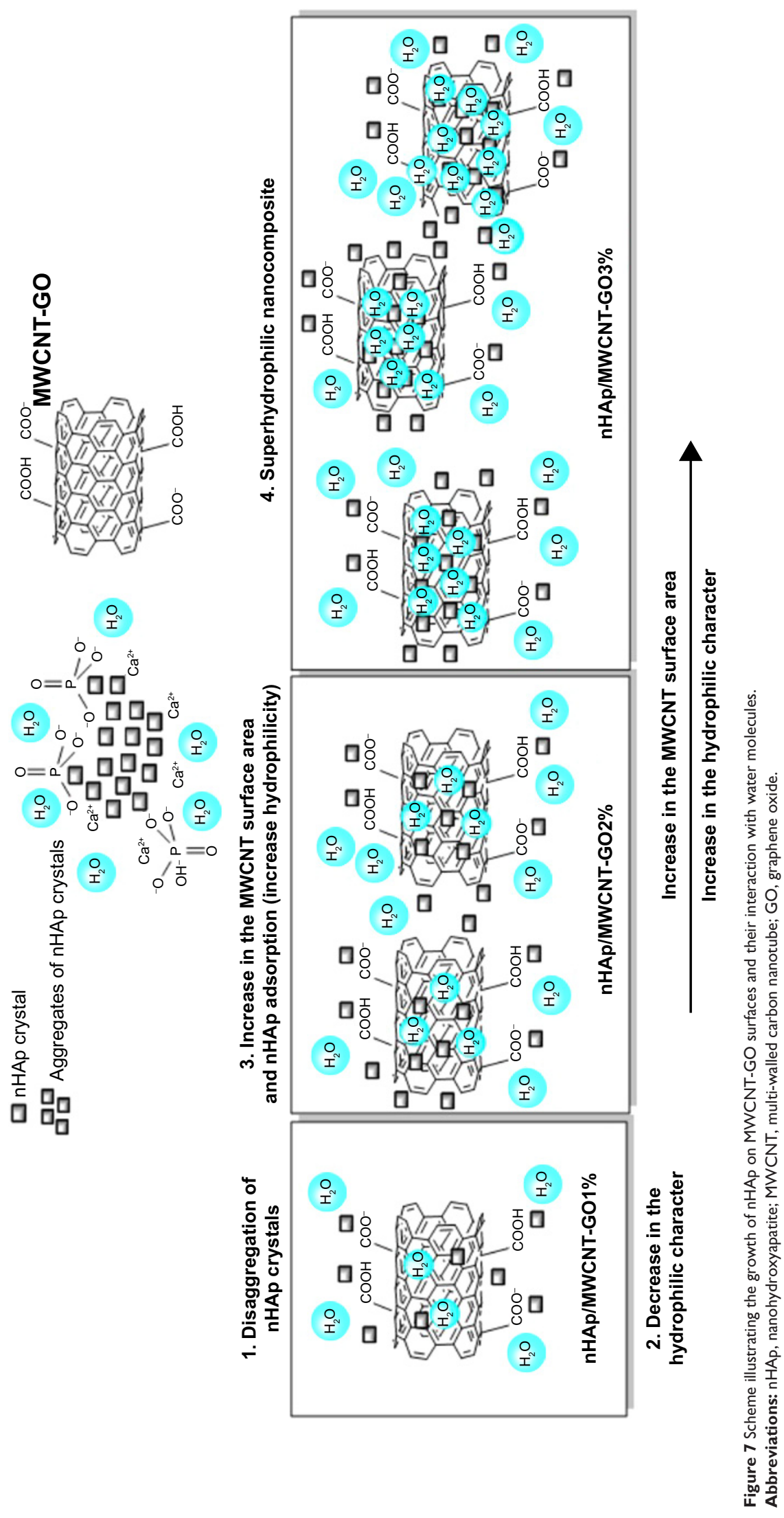
Table I Results of BET surface area analysis and mercury porosimetry ( $0.1 \mathrm{~g}$ of each sample)

\begin{tabular}{llllll}
\hline Sample & \multicolumn{2}{l}{ BET analysis } & & Mercury porosimetry \\
\cline { 2 - 5 } & Surface area $\left(\mathbf{m}^{2} \mathbf{g}^{-1}\right)$ & Mean pore diameter $(\mathbf{n m})$ & Water loss $\left(\%\right.$, up to 500 $\left.\mathbf{C}^{\circ}\right)$ & Porosity $(\%)$ \\
\hline MWCNT-GO & 39 & 3.12 & - & 75.7 \\
nHAp & 54.2 & 6.89 & 11.5 & 48.7 \\
nHAp/MWCNT-GOI\% & 64.5 & 3.09 & 3.8 & 64.2 \\
nHAp/MWCNT-GO2\% & 65.5 & 3.09 & 7.8 & 69 \\
nHAp/MWCNT-GO3\% & 73.5 & 3.45 & 16.8 & 69.4 \\
\hline
\end{tabular}

Abbreviations: BET, Brunauer-Emmett-Teller; MWCNT, multi-walled carbon nanotube; GO, graphene oxide; nHAp, nanohydroxyapatite.

at the surface of a material exposed to body fluids in order to form a surface layer of hydroxyl-carbonated apatite upon implantation, which is an essential criterion for establishing bonding with natural bone. Thus, investigating the biological behavior of scaffolds in SBF is considered the most efficient method to authenticate their bioactivity in the body environment.

Figure 8 shows the XRD patterns of nHAp, MWCNT-GO, and nHAp/MWCNT-GO nanocomposites after being soaked in SBF (1.5x) up to 21 days. The characteristic peaks of hexagonal nHAp were found at $2 \theta=31.73^{\circ}, 32.18^{\circ}, 32.86^{\circ}$, and $34.04^{\circ}$, according to JCPDS 024-0033, for all nHAp/ MWCNT nanocomposites. Thus, the MWCNT loading did not alter the nHAp nucleation and growth.

MWCNT-GO samples presented peaks at $2 \theta=26.6^{\circ}$, $43.2^{\circ}, 44^{\circ}$, and $45.1^{\circ}$, all of which are characteristic of carbon materials, according to JCPDS 00-026-1077 and
$00-001-0640$. The peaks in $2 \theta=38^{\circ}$ and $49.3^{\circ}$ are indicative that the samples still contained iron in their composition, according to JCPDS 01-085-0871. Edwards et $\mathrm{al}^{45}$ reported that even after the purification process to remove iron from the interior of the nanotubes, some catalytic particles might still be trapped unless an acidic ultrasound bath is used. The pyrolysis method used for MWCNT production does not lead to ordering in the crystalline structure, and the defects facilitate the permeability of Fe ions during the cavitation process. ${ }^{45,46}$ However, in the present investigation, we could not achieve the total removal of iron from the interior of the MWCNTs.

Table 2 shows the crystallite size, evaluated by using the Sherrer equation ${ }^{19}$ for all samples after being soaked in SBF (1.5x) for 14 and 21 days. We observed an increase in MWCNT-GO crystallite size with an increase in the time of soaking in SBF. In the nanocomposite from

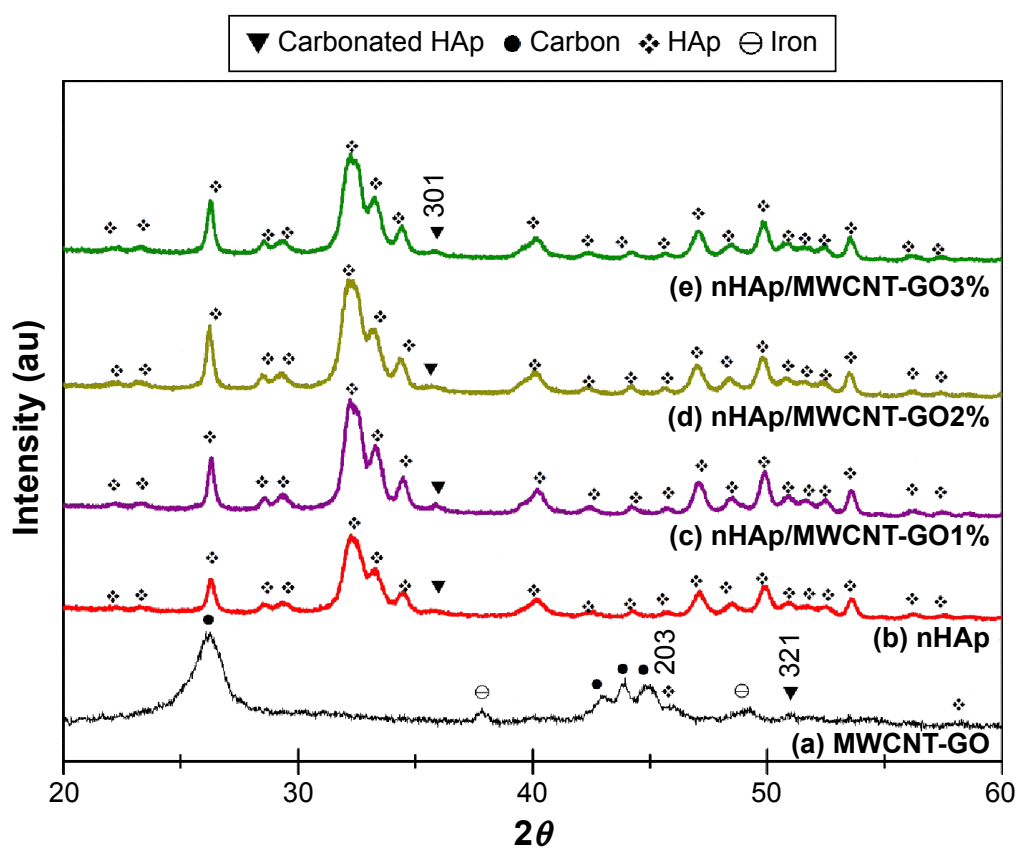

Figure 8 XRD patterns of MWCNT-GO, nHAp, and nHAp/MWCNT-GO nanocomposites after 21 days of soaking in SBF (I.5x).

Abbreviations: XRD, X-ray diffraction; MWCNT, multi-walled carbon nanotube; GO, graphene oxide; nHAp, nanohydroxyapatite; SBF, simulated body fluid; au, arbitrary units. 
Table 2 Relationship between the crystallite size and the soaking time in SBF (I.5x) for nHAp, MWCNT-GO, and nHAp/ MWCNT-GO nanocomposites

\begin{tabular}{llll}
\hline Sample & \multicolumn{3}{l}{$\begin{array}{l}\text { Crystallite size before (day 0) and } \\
\text { after soaking in SBF ( I.5x) }\end{array}$} \\
\cline { 2 - 4 } & $\mathbf{0}$ & $\mathbf{n m})$ \\
\hline MW days & 2 I days \\
nHAp & - & 12.3 & 8.9 \\
nHAp/MWCNT-GOI\% & 11.6 & 9.3 & 12.9 \\
nHAp/MWCNT-GO2\% & 15 & 14.6 & 13.3 \\
nHAp/MWCNT-GO3\% & 12.9 & 12.7 & 11.8 \\
\hline
\end{tabular}

Note: We used JCPDS 00-019-0272 (carbonated HAP) and the $\left(\begin{array}{llll}0 & 0 & 2\end{array}\right)$ to calculate crystallite size.

Abbreviations: SBF, simulated body fluid; nHAp, nanohydroxyapatite; MWCNT, multi-walled carbon nanotube; GO, graphene oxide; HAp, hydroxyapatite.

nHAp/MWCNT-GO, the increase in the time of soaking in SBF (1.5x) influenced the crystallite size, reducing it. nHAp did not present any trend regarding the crystallite size and soaking time. The nanometric size of the crystallites favors their interactions with cells in biological media. ${ }^{47}$

In the nHAp and nHAp/MWCNT-GO samples, the peak at $2 \theta=35^{\circ}$ and $98^{\circ}$ reveals the presence of carbonated HAp (CHAp), according to JCPDS 00-019-0272. Regarding the MWCNT-GO sample, we could identify a peak related to HAp at $2 \theta=45.3^{\circ}$ and another one at $2 \theta=51.19^{\circ}$ related to CHAp. Aryal et a $1^{48}$ have already reported the bioactivity of MWCNTs after soaking in SBF for 7 days. The aforementioned results demonstrate the bioactivity of all samples, which were able to interact with SBF and consequently led to precipitation of CHAp on their surfaces.
Figure 9 shows the ATR-FTIR spectra of nHAp and nHAp/MWCNT-GO nanocomposites after 21 days of being soaked in SBF $(1.5 x)$. The absorbance of the $\mathrm{CO}_{3}{ }^{2-}$ group from HAp was found in the $870-880 \mathrm{~cm}^{-1}\left(v_{2}\right.$, out-of-plane vibration $)$ and 1,400 $1,640 \mathrm{~cm}^{-1}$ range $\left(v_{3} \text {, asymmetric stretching vibration }\right)^{49,50}$ and at $1,415 \mathrm{~cm}^{-1} \cdot{ }^{51}$ At 1,020 and $1,200 \mathrm{~cm}^{-1}$, we observed the $\mathrm{P}-\mathrm{O}$ asymmetric stretching from the $\mathrm{PO}_{4}{ }^{3-}$ group. ${ }^{50,52} \mathrm{We}$ found these bands in all samples analyzed.

According to LeGeros, the relation between the intensity of the carbonate group $\left(1,420 \mathrm{~cm}^{-1}, \mathrm{CI}\right)$ and intensity of the phosphate $\left(1,010 \mathrm{~cm}^{-1}, \mathrm{PI}\right), \mathrm{CI} / \mathrm{PI}$, can be used to estimate the $\mathrm{CO}_{3}{ }^{2-}$ content in the nHAp structure (Equation 2)..$^{40}$

$$
y_{\mathrm{CO}_{3}}=10.134\left(\frac{\mathrm{CI}}{\mathrm{PI}}\right)+0.2134
$$

Table 3 shows the data for the $\mathrm{CO}_{3}{ }^{2-}$ content (estimated by Equation 2$)^{40}$ obtained by the ATR-FTIR analysis before soaking the samples in SBF (control) and after they were soaked in SBF (1.5x) for 14 and 21 days. We observed that the carbonate content increased with the increase of the immersion time, which was an indication of $\mathrm{CO}_{3}{ }^{2-}$ deposition on the samples, according to XRD results.

The FEG-SEM micrographs of the samples before (control) and after soaking for 21 days in SBF (1.5x) are depicted in Figure 10. We observed apatite plaques on the MWCNTs after 21 days (indicated by circles), pointing out their bioactivity. All the samples after 21 days, with different

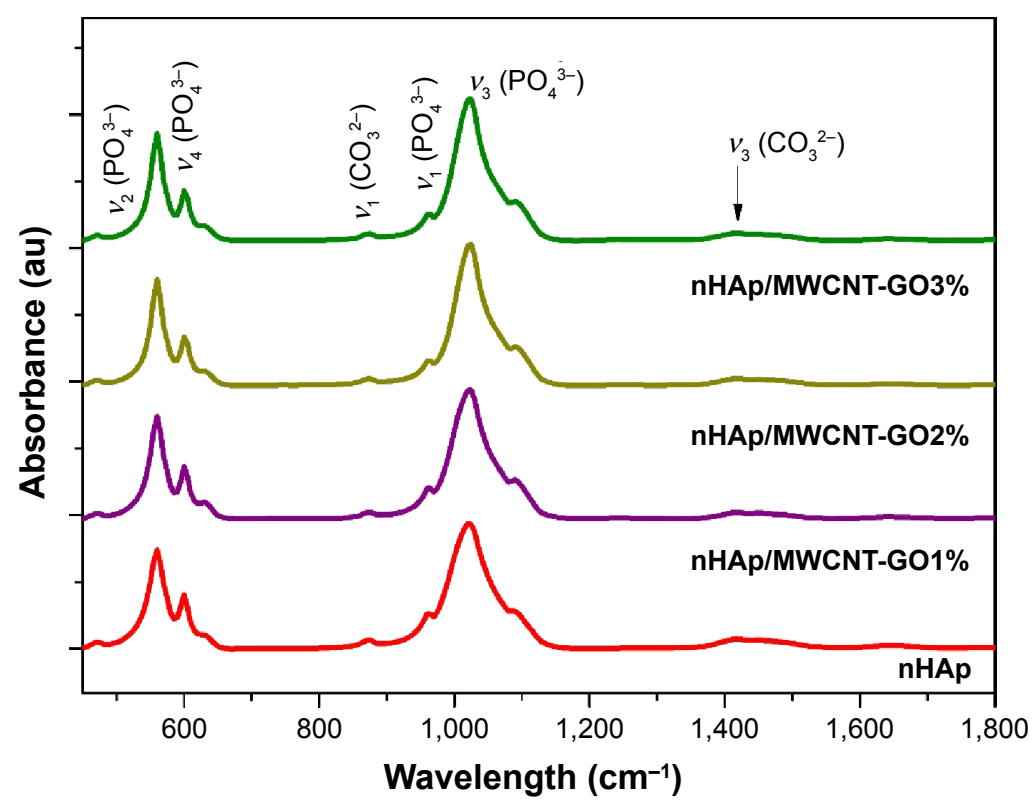

Figure 9 ATR-FTIR spectra of $\mathrm{nHAp}$ and $\mathrm{nHAp} / \mathrm{MWCNT}-\mathrm{GO}$ nanocomposites after 21 days of being soaked in SBF (I.5x).

Abbreviations: ATR-FTIR, attenuated transmission reflectance Fourier transform infrared; nHAp, nanohydroxyapatite; MWCNT, multi-walled carbon nanotube; GO, graphene oxide; SBF, simulated body fluid; au, arbitrary units. 
Table $3 \mathrm{CO}_{3}{ }^{2-}$ content (ATR-FTIR analysis, estimated by Equation 2) on the samples before (control) and after soaking in $\operatorname{SBF}(1.5 \mathrm{x})$ during 14 and 21 days

\begin{tabular}{llll}
\hline Sample & Control & |4 days & 2I days \\
\hline MWCNT-GO & 0 & 1.46 & 1.99 \\
nHAP & 0.44 & 0.91 & 1.06 \\
nHAP/MWCNT-GOI\% & 0.45 & 0.70 & 0.77 \\
nHAP/MWCNT-GO2\% & 0.64 & 0.79 & 0.80 \\
nHAP/MWCNT-GO3\% & 0.74 & 0.80 & 0.85 \\
\hline
\end{tabular}

Abbreviations: ATR-FTIR, attenuated transmission reflectance Fourier transform infrared; SBF, simulated body fluid; MWCNT, multi-walled carbon nanotube; $\mathrm{GO}$, graphene oxide; nHAp, nanohydroxyapatite.

MWCNT-GO contents, presented similar morphology as their respective controls. For all nanocomposites (Figure 10E-J), we observed MWCNT-GO filaments covered by apatite plaques (indicated by white arrows).

Kokubo and Takadama reported that the formation of apatite plaques on a material is a useful indicator to predict the in vivo bioactivity for bone regeneration applications. ${ }^{53}$

Calcium is a common ion in SBFs and bioactive materials, and plays an important role in the process of dissolution/ precipitation. Its release from the surface of the substrate to the adjacent electrolyte triggers the formation of the biologically active layer and stimulates bone growth. ${ }^{54}$ Therefore, on immersion in SBF, all the composites could exhibit a negative surface charge by exposing hydroxyl and phosphate groups. ${ }^{55}$ This negative charge on the surface of the HAp is beneficial in the specific interaction with the positive calcium ions in the fluid, consequently forming a CHAp..$^{55}$

Interestingly, nHAp/MWCNT-GO composites presented more carbonate content than nHAp alone (Table 2). This was expected due to higher aspect ratio and total porosity measured by porosimetry (Table 1). On the other hand, the novel nanocomposites presented excellent bioactivity properties due to release of CHAp to the media for up to 21 days, and consequently, the decrease of measured values (Table 3). It was very illustrative because we proved that nHAp/MWCNT-GO composites can release carbonate to biological media and probably induce biological process-like apatite precipitation. ${ }^{56}$

\section{Biological assays}

\section{Cell culture}

In our pilot studies, it was observed that the direct application of the scaffolds (in powder form) on the cells was not suitable for microplate readings, given the amount of residue in the bottom of the wells with cells attached to them. To avoid this issue, it was decided to mix the scaffolds with hyaluronic acid, a well-known scaffold material, ${ }^{57}$ which would allow us to apply the scaffold on the top of the transwell membranes. Using this approach, the results confirmed what was observed morphologically: all formulations of MWCNTs showed high levels of cytocompatibility, allowing cells to proliferate with no remarkable cell death. This is shown in Figure 11.
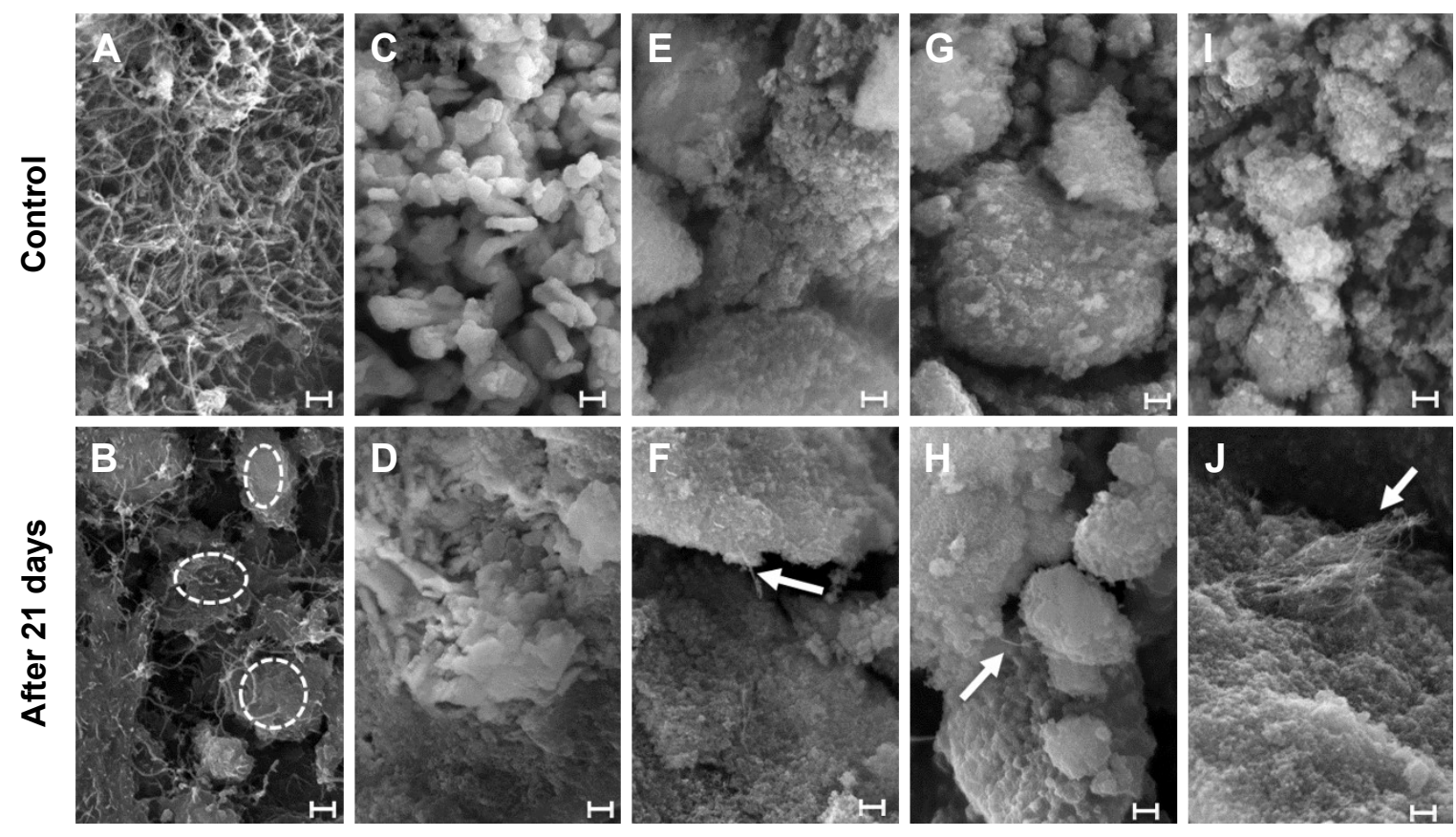

Figure 10 SEM micrographs before and after soaking in SBF for 21 days (I.5x).

Notes: (A and B) MWCNT-GO. (C and D) nHAp. (E and F) nHAp/MWCNT-GOI\%. (G and H) nHAp/MWCNT-GO2\%. (I and J) nHAp/MWCNT-GO3\%. Scale bar: I $\mu$ m. White circles indicate apatite plaques covering MWCNT-GO. White arrows indicate MWCNT-GO filaments covered by apatite plaques.

Abbreviations: SEM, scanning electron microscopy; SBF, simulated body fluid; MWCNT, multi-walled carbon nanotube; GO, graphene oxide; nHAp, nanohydroxyapatite. 


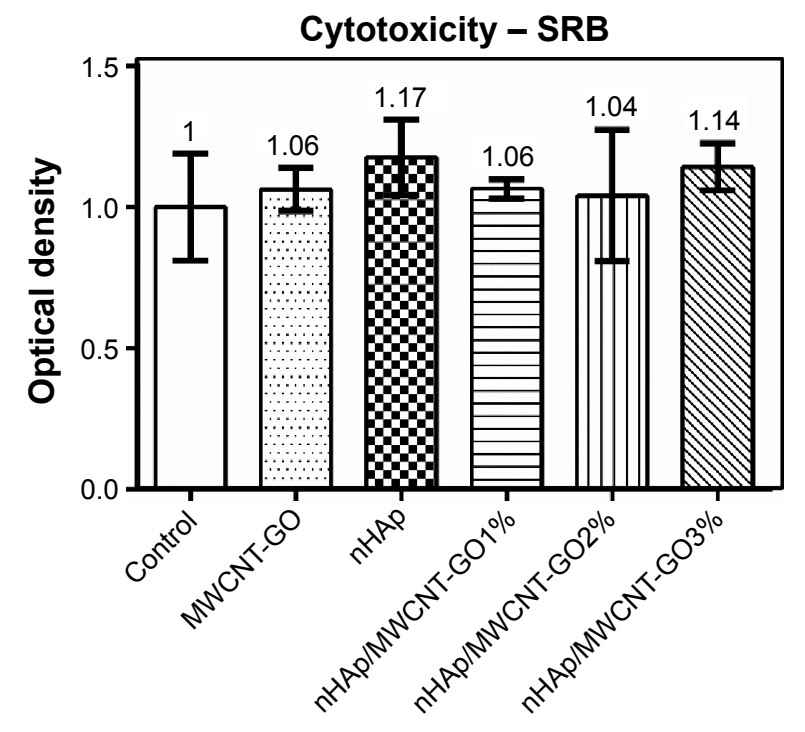

Figure I I Cellular viability of MG-63 cells after 7 days of incubation with controls, MWCNT-GO, nHAp, and nHAp/MWCNT-GO nanocomposites.

Note: Values are expressed as mean \pm SD $(n=3)$.

Abbreviations: MWCNT, multi-walled carbon nanotube; GO, graphene oxide; nHAp, nanohydroxyapatite; SD, standard deviation; SRB, sulforhodamine B.

These data were also reported in other studies using different approaches. ${ }^{34,47,58}$ It is important to emphasize that, independent of the cell type, the cytotoxicity assessment method, and the form of application of the material on the cells, all of these studies support that MWCNT scaffolds are a viable and safe structure for cell adhesion and growth.

\section{Bactericidal properties}

Most impressively, this study highlights for the first time that the nHAp/MWCNT-GO nanocomposites showed significant antimicrobial activity without the use of antibiotics (Figure 12). Specifically, against $E$. coli, we observed a reduction of
$69 \%$ viability with $\mathrm{nHAp} / \mathrm{MWCNT}-\mathrm{GO} 3 \%$ at $100 \mu \mathrm{g} \mathrm{mL}$ (Figure 12A). Against $S$. aureus, we observed a reduction of $50 \%$ viability with nHAp/MWCNT-GO1\% and $2 \%$ at $100 \mu \mathrm{g} \mathrm{mL}^{-1}$ (Figure 12B). These results are in accordance with those of Arias and Yang, and Liu et al, although those experiments were conducted differently and substrates were formulated differently. ${ }^{59,60}$ The same observation was reported by Dong et al where single-walled carbon nanotube (SWCNT) tests indicated that the nanotube concentration is the deciding factor for an antibacterial effect. ${ }^{61}$ Our results showed that increasing the MWCNT concentration (from 10 to $100 \mu \mathrm{g} \mathrm{mL}^{-1}$ ) led to increases in the bactericidal effect against $E$. coli and $S$. aureus, and these results are very similar to those observed in a study by Liu et al, which reported that the death rate of $E$. coli increased with an increase in SWCNT concentration from 5 to $80 \mu \mathrm{g} \mathrm{mL}{ }^{-1}{ }^{60}$

It is not clear yet as to how exactly CNTs kill microbes. A possible mechanism was proposed by Kang et al where the antimicrobial activity of SWCNTs was induced by direct physical contact between bacterial cell membranes and SWCNT aggregates. ${ }^{62} \mathrm{We}$ observed that increasing the concentration of nHAp/MWCNT-GO1\%, 2\%, and 3\% from 10 to $100 \mu \mathrm{g} \mathrm{mL}^{-1}$ caused cell death, and thereby, we propose that bacterial membranes may be damaged after contact with CNTs, degrading bacterial cell integrity and therefore causing cell death. In a Gram-negative strain, such as E. coli, an outer plasma membrane containing lipopolysaccharide encases a thinner layer of peptidoglycan tethered to the outer leaflet of the cytoplasmic membrane. In Gram-positive bacteria, such as $S$. aureus, the cell wall comprises multiple layers of peptidoglycan interspersed with teichoic acid and lipoteichoic acid. ${ }^{63}$ The bactericidal effect was more expressive in $E$. coli
A

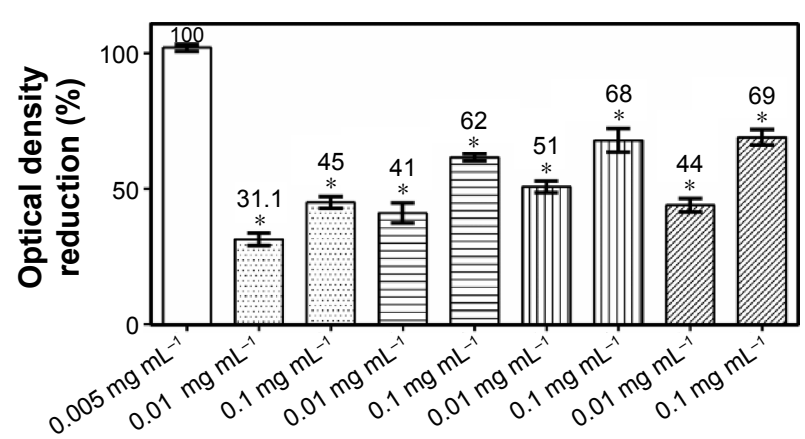

B Bactericidal effect - Staphylococcus aureus

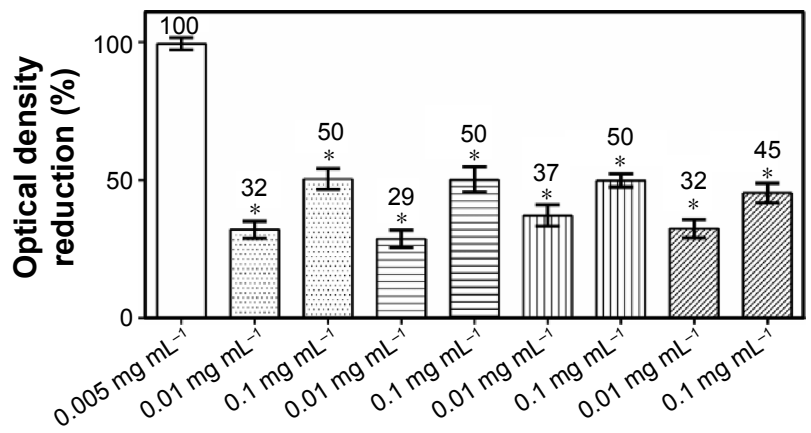

Gentamicin 圆 MWCNT-Go 目 nHAp/MWCNT-GO1\% 血 nHAp/MWCNT-GO2\% 四 nHAp/MWCNT-GO3\%

Figure 12 Bactericidal effect of nHAp/MWCNT-GO nanocomposites.

Notes: Bactericidal effect against (A) Escherichia coli and (B) Staphylococcus aureus. Values are reported as mean $\pm S D(n=3)$. $* p<0.05$.

Abbreviations: SD, standard deviation; MWCNT, multi-walled carbon nanotube; GO, graphene oxide; nHAp, nanohydroxyapatite. 
than in $S$. aureus, and these results can be justified by the different compositions of bacterial cell wall. An alternative mechanism for the antibacterial properties of CNTs could be related to their surface energy where antibacterial proteins (such as mucin) contained in serum preferentially adsorb to the surfaces to inhibit bacterial attachment. Clearly, additional studies are necessary to elucidate by what mechanism CNTs can reduce bacterial growth without using antibiotics and without adversely affecting osteoblasts.

\section{Conclusion}

In this investigation, we successfully prepared a series of nHAp/MWCNT-GO nanocomposites, in order to produce a material that could combine similar bone characteristics and enhanced physicochemical properties necessary for orthopedic applications. We used different MWCNT-GO concentrations (1-3 wt \%) aiming at a better understanding of the dependence of the final properties of the material on MWCNT content. By TEM analysis, we observed that the synthesized nHAp particles, which were homogeneously distributed along the MWCNT surfaces, corresponded to dense agglomerates of small nanorod particles $(\sim 15 \mathrm{~nm}$ in diameter and 45-70 $\mathrm{nm}$ in length). BET analysis showed that all nHAp/MWCNT-GO scaffolds were highly porous ( $\sim 60 \%-70 \%)$, which is desirable for cell proliferation and infiltration for bone regeneration purposes. TGA indicated that the increase in MWCNT-GO concentration would have favored nHAp adsorption and consequent increase in the local and global interactions with water molecules, leading to nanocomposites with higher hydrophilic character. We showed that all nanocomposites were bioactive, since CHAp was found after 21 days of soaking in SBF (1.5x). All nanocomposites were found suitable for biomedical applications, with a demonstrated bactericidal effect against $S$. aureus and E. coli, and no osteoblast cytotoxicity was observed. All of the aforementioned properties make these materials very attractive for numerous bone tissue engineering applications, either as a matrix or as a reinforcement material in polymeric nanocomposites.

\section{Acknowledgments}

Regarding the financial support to this work, the authors would like to thank the Coordination for the Improvement of Higher Education Personnel (PVEs-CAPES, 88887.095044/2015-00), the National Council for Scientific and Technological Development (CNPq grant474090/2013-2), the Sao Paulo Research Foundation (FAPESP, grants 2011/17877-7, 2011/20345-7 and 2013/20054-8), and the
Brazilian Innovation Agency (FINEP; 0113042800). BVMR would also like to thank the FAPESP for the postdoctoral fellowship (2015/08523-8). The authors would also like to thank the Northeastern University for sponsoring this study.

\section{Disclosure}

The authors report no conflicts of interest in this work.

\section{References}

1. Pirraco R, Reis R. Tissue engineering: new tools for old problems. Stem Cell Rev. 2015;11(3):373-375.

2. Hutmacher DW. Scaffolds in tissue engineering bone and cartilage. Biomaterials. 2000;21(24):2529-2543.

3. Griffith LG, Naughton G. Tissue engineering - current challenges and expanding opportunities. Science. 2002;295(5557):1009-1014.

4. Venkatesan J, Kim SK. Nano-hydroxyapatite composite biomaterials for bone tissue engineering - a review. J Biomed Nanotechnol. 2014;10(10): 3124-3140.

5. Campana V, Milano G, Pagano E, et al. Bone substitutes in orthopaedic surgery: from basic science to clinical practice. JMater Sci Mater Med. 2014;25(10):2445-2461.

6. Hernigou P, Homma Y. Tissue bioengineering in orthopedics. Clin Cases Miner Bone Metab. 2012;9(1):21-23.

7. Roveri N, Iafisco M. Evolving application of biomimetic nanostructured hydroxyapatite. Nanotechnol Sci Appl. 2010;3:107-125.

8. Thomas V, Dean DR, Vohra YK. Nanostructured biomaterials for regenerative medicine. Curr Nanosci. 2006;2(3):155-177.

9. Siqueira IA, Corat MA, Cavalcanti B, et al. In vitro and in vivo studies of novel poly(D,L-lactic acid), superhydrophilic carbon nanotubes, and nanohydroxyapatite scaffolds for bone regeneration. ACS Appl Mater Interfaces. 2015;7(18):9385-9398.

10. Venkatesan J, Pallela R, Kim SK. Applications of carbon nanomaterials in bone tissue engineering. J Biomed Nanotechnol. 2014;10(10): 3105-3123.

11. Zanin H, Rosa CMR, Eliaz N, May PW, Marciano FR, Lobo AO. Assisted deposition of nano-hydroxyapatite onto exfoliated carbon nanotube oxide scaffolds. Nanoscale. 2015;7(22):10218-10232.

12. Allen MJ, Tung VC, Kaner RB. Honeycomb carbon: a review of graphene. Chem Rev. 2010;110(1):132-145.

13. Balandin AA. Thermal properties of graphene and nanostructured carbon materials. Nat Mater. 2011;10(8):569-581.

14. Mittal G, Dhand V, Rhee KY, Park SJ, Lee WR. A review on carbon nanotubes and graphene as fillers in reinforced polymer nanocomposites. J Ind Eng Chem. 2015;21:11-25.

15. Wang S, Yang B, Yuan J, Si Y, Chen H. Large-scale molecular simulations on the mechanical response and failure behavior of a defective graphene: cases of 5-8-5 defects. Sci Rep. 2015;5:14957.

16. Yang B, Wang S, Guo Y, et al. Strength and failure behavior of a graphene sheet containing bi-grain-boundaries. RSC Adv. 2014;4(97): 54677-54683.

17. GrinetMAVM,ZaninH,Campos Granato AE, PorcionattoM,MarcianoFR, Lobo AO. Fast preparation of free-standing nanohydroxyapatitevertically aligned carbon nanotube scaffolds. J Mater Chem B Mater Biol Med. 2014;2(9):1196-1204.

18. Lobo AO, Corat MA, Ramos SC, et al. Fast preparation of hydroxyapatite/superhydrophilic vertically aligned multiwalled carbon nanotube composites for bioactive application. Langmuir. 2010;26(23): 18308-18314.

19. Lobo AO, Zanin H, Siqueira IA, Leite NC, Marciano FR, Corat EJ. Effect of ultrasound irradiation on the production of nHAp/MWCNT nanocomposites. Mater Sci Eng C Mater Biol Appl. 2013;33(7): 4305-4312. 
20. Lahiri D, Benaduce AP, Kos L, Agarwal A. Quantification of carbon nanotube induced adhesion of osteoblast on hydroxyapatite using nanoscratch technique. Nanotechnology. 2011;22(35):355703.

21. Balani K, Anderson R, Laha T, et al. Plasma-sprayed carbon nanotube reinforced hydroxyapatite coatings and their interaction with human osteoblasts in vitro. Biomaterials. 2007;28(4):618-624.

22. Kim D-Y, Han Y-H, Lee JH, Kang I-K, Jang B-K, Kim S. Characterization of multiwalled carbon nanotube-reinforced hydroxyapatite composites consolidated by spark plasma sintering. Biomed Res Int. 2014;2014:10.

23. Im O, Li J, Wang M, Zhang LG, Keidar M. Biomimetic three-dimensional nanocrystalline hydroxyapatite and magnetically synthesized single-walled carbon nanotube chitosan nanocomposite for bone regeneration. Int J Nanomedicine. 2012;7:2087-2099.

24. Antunes EF, de Resende VG, Mengui UA, Cunha JBM, Corat EJ, Massi M. Analyses of residual iron in carbon nanotubes produced by camphor/ferrocene pyrolysis and purified by high temperature annealing. Appl Surf Sci. 2011;257(18):8038-8043.

25. Ramos SC, Lobo AO, de Vasconcelos G, Antunes EF, Trava-Airoldi VJ, Corat EJ. Influence of polar groups on the wetting properties of vertically aligned multiwalled carbon nanotube surfaces. Theor Chem Acc. 2011;130(4-6):1061-1069.

26. Barbosa MC, Messmer NR, Brazil TR, Marciano FR, Lobo AO. The effect of ultrasonic irradiation on the crystallinity of nano-hydroxyapatite produced via the wet chemical method. Mater Sci Eng C Mater Biol Appl. 2013;33(5):2620-2625.

27. Kokubo T. Surface-chemistry of bioactive glass-ceramics. J Non Cryst Solids. 1990;120(1-3):138-151.

28. Sezonov G, Joseleau-Petit D, D'Ari R. Escherichia coli physiology in Luria-Bertani broth. J Bacteriol. 2007;189(23):8746-8749.

29. Streker K, Freiberg C, Labischinski H, Hacker J, Ohlsen K. Staphylococcus aureus NfrA (SA0367) is a flavin mononucleotide-dependent NADPH oxidase involved in oxidative stress response. J Bacteriol. 2005; 187(7):2249-2256.

30. Liu T, Tang HQ, Cai XM, et al. A study on bactericidal properties of Ag coated carbon nanotubes. Nucl Instrum Methods Phys Res B. 2007; 264(2):282-286

31. Zanin H, Saito E, Marciano FR, et al. Fast preparation of nanohydroxyapatite/superhydrophilic reduced graphene oxide composites for bioactive applications. J Mater Chem B Mater Biol Med. 2013;1(38): 4947-4955.

32. Antunes EF, Lobo AO, Corat EJ, Trava-Airoldi VJ, Martin AA, Veríssimo C. Comparative study of first- and second-order Raman spectra of MWCNT at visible and infrared laser excitation. Carbon. 2006;44(11):2202-2211.

33. Lobo AO, Ramos SC, Antunes EF, Marciano FR, Trava-Airoldi VJ, Corat EJ. Fast functionalization of vertically aligned multiwalled carbon nanotubes using oxygen plasma. Mater Lett. 2012;70:89-93.

34. Hollanda LM, Lobo AO, Lancellotti M, Berni E, Corat EJ, Zanin H. Graphene and carbon nanotube nanocomposite for gene transfection. Mater Sci Eng C Mater Biol Appl. 2014;39:288-298.

35. Zhao Q, Shen Y, Ji M, Zhang L, Jiang T, Li C. Effect of carbon nanotube addition on friction coefficient of nanotubes/hydroxyapatite composites. J Ind Eng Chem. 2014;20(2):544-548.

36. Núñez JD, Benito AM, González R, Aragón J, Arenal R, Maser WK. Integration and bioactivity of hydroxyapatite grown on carbon nanotubes and graphene oxide. Carbon. 2014;79:590-604.

37. Aryal S, Bahadur KCR, Dharmaraj N, Kim K-W, Kim HY. Synthesis and characterization of hydroxyapatite using carbon nanotubes as a nano-matrix. Scr Mater. 2006;54(2):131-135.

38. Liao S, Xu G, Wang W, et al. Self-assembly of nano-hydroxyapatite on multi-walled carbon nanotubes. Acta Biomater. 2007;3(5): 669-675.

39. Fan Z, Wang J, Wang Z, et al. One-pot synthesis of graphene/ hydroxyapatite nanorod composite for tissue engineering. Carbon. 2014; $66: 407-416$
40. LeGeros RZ. Calcium phosphates in oral biology and medicine. Monogr Oral Sci. 1991;15:1-201.

41. Hwang Y, Kim M, Kim J. Improvement of the mechanical properties and thermal conductivity of poly(ether-ether-ketone) with the addition of graphene oxide-carbon nanotube hybrid fillers. Compos Part A Appl Sci Manuf. 2013;55:195-202.

42. Meejoo S, Maneeprakorn W, Winotai P. Phase and thermal stability of nanocrystalline hydroxyapatite prepared via microwave heating. Thermochim Acta. 2006;447(1):115-120.

43. Jakubowski W, Ślósarczyk A, Paszkiewicz Z, Szymański W, Walkowiak B. Bacterial colonisation of bioceramic surfaces. Adv Appl Ceram. 2008;107(4):217-221.

44. Schwartz Z, Boyan BD. Underlying mechanisms at the bone--biomaterial interface. J Cell Biochem. 1994;56(3):340-347.

45. Edwards ER, Antunes EF, Botelho EC, Baldan MR, Corat EJ. Evaluation of residual iron in carbon nanotubes purified by acid treatments. Appl Surf Sci. 2011;258(2):641-648.

46. Yuan J-M, Chen X-H, Chen X-H, Fan Z-F, Yang X-G, Chen Z-H. An easy method for purifying multi-walled carbon nanotubes by chlorine oxidation. Carbon. 2008;46(9):1266-1269.

47. He HW, Li GD, Li B, Chen ZQ. Effects of surface microstructure of hydroxyapatite on protein adsorption and biological performance of osteoblasts. Appl Surf Sci. 2008;255(2):565-567.

48. Aryal $\mathrm{S}$, et al. Carbon nanotubes assisted biomimetic synthesis of hydroxyapatite from simulated body fluid. Materials Science and Engineering. 2006;202-207.

49. Deplaine H, Lebourg M, Ripalda P, et al. Biomimetic hydroxyapatite coating on pore walls improves osteointegration of poly(L-lactic acid) scaffolds. J Biomed Mater Res B Appl Biomater. 2013;101(1): 173-186.

50. Hoppe A, Will J, Detsch R, Boccaccini AR, Greil P. Formation and in vitro biocompatibility of biomimetic hydroxyapatite coatings on chemically treated carbon substrates. J Biomed Mater Res Part A. 2014; 102(1):193-204.

51. Giardina MA, Fanovich MA. Synthesis of nanocrystalline hydroxyapatite from $\mathrm{Ca}(\mathrm{OH}) 2$ and $\mathrm{H} 3 \mathrm{PO} 4$ assisted by ultrasonic irradiation. Ceram Int. 2010;36(6):1961-1969.

52. Aryal S, Bhattarai SR, Remant Bahadur KC, Khil MS, Lee D-R, Kim HY. Carbon nanotubes assisted biomimetic synthesis of hydroxyapatite from simulated body fluid. Mater Sci Eng A Struct Mater. 2006; 426(1-2):202-207.

53. Kokubo T, Takadama H. How useful is SBF in predicting in vivo bone bioactivity? Biomaterials. 2006;27(15):2907-2915.

54. Eliaz N, Shmueli S, Shur I, Benayahu D, Aronov D, Rosenman G. The effect of surface treatment on the surface texture and contact angle of electrochemically deposited hydroxyapatite coating and on its interaction with bone-forming cells. Acta Biomater. 2009;5(8):3178-3191.

55. Kim HM, Himeno T, Kokubo T, Nakamura T. Process and kinetics of bonelike apatite formation on sintered hydroxyapatite in a simulated body fluid. Biomaterials. 2005;26(21):4366-4373.

56. Hashmi MU, Shah SA, Alam S, Shamim A. Dissolution behavior of bioactive glass ceramics with different $\mathrm{Cao} / \mathrm{Mgo}$ ratios. Ceram-Silik. 2010;54(1):8-13.

57. Khan F, Ahmad SR. Polysaccharides and their derivatives for versatile tissue engineering application. Macromol Biosci. 2013;13(4):395-421.

58. Mwenifumbo S, Shaffer MS, Stevens MM. Exploring cellular behaviour with multi-walled carbon nanotube constructs. J Mater Chem. 2007; 17(19):1894-1902.

59. Arias LR, Yang L. Inactivation of bacterial pathogens by carbon nanotubes in suspensions. Langmuir. 2009;25(5):3003-3012.

60. Liu S, Wei L, Hao L, et al. Sharper and faster "nano darts" kill more bacteria: a study of antibacterial activity of individually dispersed pristine single-walled carbon nanotube. ACS Nano. 2009;3(12):3891-3902.

61. Dong L, Henderson A, Field C. Antimicrobial activity of single-walled carbon nanotubes suspended in different surfactants. J Nanotechnol. 2012;2012:928924 
62. Kang S, Pinault M, Pfefferle LD, Elimelech M. Single-walled carbon nanotubes exhibit strong antimicrobial activity. Langmuir. 2007; 23(17):8670-8673.
63. Yount NY, Yeaman MR. Peptide antimicrobials: cell wall as a bacterial target. Ann N Y Acad Sci. 2013;1277:127-138

\section{Publish your work in this journal}

The International Journal of Nanomedicine is an international, peerreviewed journal focusing on the application of nanotechnology in diagnostics, therapeutics, and drug delivery systems throughout the biomedical field. This journal is indexed on PubMed Central, MedLine, CAS, SciSearch $\AA$, Current Contents ${ }^{\circledR} /$ Clinical Medicine,
Journal Citation Reports/Science Edition, EMBase, Scopus and the Elsevier Bibliographic databases. The manuscript management system is completely online and includes a very quick and fair peer-review system, which is all easy to use. Visit http://www.dovepress.com/ testimonials.php to read real quotes from published authors.

Submit your manuscript here: http://www.dovepress.com/international-journal-of-nanomedicine-journal 